\title{
Unraveling Massive Crocins Transport and Accumulation through Proteome and Microscopy Tools during the Development of Saffron Stigma
}

\author{
Lourdes Gómez-Gómez ${ }^{1}$, Verónica Parra-Vega ${ }^{2}$, Alba Rivas-Sendra ${ }^{2}$, Jose M. Seguí-Simarro ${ }^{2}$, \\ Rosa Victoria Molina ${ }^{3}$, Claudia Pallotti ${ }^{3}$, Ángela Rubio-Moraga ${ }^{1}$, Gianfranco Diretto ${ }^{4}$, \\ Alicia Prieto ${ }^{5}$ and Oussama Ahrazem ${ }^{1,6, *}$ \\ 1 Botanical Institute, Department of Science Technology, Agroforestry and Genetics, Faculty of Pharmacy, \\ University of Castilla-La Mancha, Campus Universitario s/n, 02071 Albacete, Spain; \\ marialourdes.gomez@uclm.es (L.G.-G.); angela.rubio@uclm.es (A.R.-M.) \\ 2 Cell Biology Group, COMAV Institute, Polytechnic University of Valencia, 46071 Valencia, Spain; \\ veparve@upv.es (V.P.-V.); alriis@upvnet.upv.es (A.R.-S.); seguisim@btc.upv.es (J.M.S.-S.) \\ 3 Department of Vegetal Biology, Polytechnic University of Valencia, 46071 Valencia, Spain; \\ rvmolina@bvg.upv.es (R.V.M.); pallotti@bvg.upv.es (C.P.) \\ 4 Italian National Agency for New Technologies, Energy, and Sustainable Development, \\ Casaccia Research Centre, 00123 Rome, Italy; gianfranco.diretto@enea.it \\ 5 The Biological Research Center (CIB) Spanish National Research Council (CSIC), C/Ramiro de Maeztu 9, \\ 28040 Madrid, Spain; aliprieto@cib.csic.es \\ 6 Faculty of Environmental Sciences and Biochemistry Toledo, University of Castilla-La Mancha, \\ Campus Tecnológico de la Fábrica de Armas, Avda, Carlos III, s/n, 45071 Toledo, Spain \\ * Correspondence: oussama.ahrazem@uclm.es; Tel.: +34-967-599-200; Fax: +34-967-599-238
}

Academic Editor: Setsuko Komatsu

Received: 22 November 2016; Accepted: 24 December 2016; Published: 1 January 2017

\begin{abstract}
Crocins, the glucosides of crocetin, are present at high concentrations in saffron stigmas and accumulate in the vacuole. However, the biogenesis of the saffron chromoplast, the changes during the development of the stigma and the transport of crocins to the vacuole, are processes that remain poorly understood. We studied the process of chromoplast differentiation in saffron throughout stigma development by means of transmission electron microscopy. Our results provided an overview of a massive transport of crocins to the vacuole in the later developmental stages, when electron dense drops of a much greater size than plastoglobules (here defined "crocinoplast") were observed in the chromoplast, connected to the vacuole with a subsequent transfer of these large globules inside the vacuole. A proteome analysis of chromoplasts from saffron stigma allowed the identification of several well-known plastid proteins and new candidates involved in crocetin metabolism. Furthermore, expressions throughout five developmental stages of candidate genes responsible for carotenoid and apocarotenoid biogenesis, crocins transport to the vacuole and starch metabolism were analyzed. Correlation matrices and networks were exploited to identify a series of transcripts highly associated to crocetin (such as 1-Deoxy-D-xylulose 5-phosphate synthase (DXS), 1-Deoxy-D-xylulose 5-phosphate reductoisomerase (DXR), carotenoid isomerase (CRTISO), Crocetin glucosyltransferase 2 (UGT2), etc.) and crocin (e.g., $\zeta$-carotene desaturase (ZDS) and plastid-lipid-associated proteins (PLAP2)) accumulation; in addition, candidate aldehyde dehydrogenase $(A D H)$ genes were highlighted.
\end{abstract}

Keywords: chromoplast; crocetin; crocins; proteome; transport

\section{Introduction}

Saffron spice is produced from the dried stigmas of Crocus sativus L., these long scarlet stigmas of saffron are highly valued for flavoring and coloring foods and are among the most expensive 
spices in the world. The compounds responsible for the organoleptic properties of the spice are the following apocarotenoids: crocins, the glucosylated derivatives of the apocarotenoid crocetin, which gives stigma its red coloration, and picrocrocin, a monoglucosylated derivative of 4-hydroxy-2,6,6trimethyl-1-cyclohexene-1-carboxaldehyde (HTCC), which provides saffron its bitter taste, while its degradation generates safranal, responsible for the aroma [1]. Saffron has been used in traditional medicine and has been reported to have a variety of health benefits [2]. Among these properties, saffron has been used as analgesic and sedative and shows growth inhibition against certain lines of malignant cells, suggesting that saffron might be used as an anticancer agent [3]. These properties are due to the apocarotenoids crocetin, crocins and picrocrocin, the main components of the stigma and spice, which are also present in other Crocus species, although in minor quantities [4,5]. Zeaxanthin, synthesized in the saffron chromoplast through the carotenoid biosynthetic pathway $[4,6]$, is the precursor of these saffron apocarotenoids [7]. The enzyme carotenoid cleavage dioxygenase 2 (CCD2), localized in the chromoplast [8], catalyzed the cleavage of the 7,8 and $7^{\prime}, 8^{\prime}$ double bonds of this carotenoid to render one molecule of crocetin dialdehyde and two molecules of 8 -hydroxy- $\beta$-cyclocitral [9]. These products are further oxidated and glucosylated [10], generating soluble apocarotenoids which accumulate in the vacuole [11].

Chromoplasts are present in many flowers and fruits giving them the yellow, orange and red colors [12]. They are also found in some roots, and tubers such as carrots, and sweet potatoes [13], respectively. In saffron, reticulotubular structures in the chromoplast made up of a reticulum of tubules are abundant, but vesicle and globule forms also coexist [11].

The process of crocins transport from the chromoplast to the vacuole is not fully understood. To address this question, we monitored chromoplast development during stigma growth by means of transmission electron microscopy. Furthermore, we checked the expression of the putative genes responsible for chromoplast biogenesis, crocetin formation and crocins transport to the vacuole and we used a series of bioinformatics approaches, mainly based on correlation analysis, to evidence transcripts potentially involved in apocarotenoid synthesis, movement and storage. Finally, we analyzed the chromoplast proteome from the stigma at the red-scarlet stage by through nanoscale liquid chromatography coupled to tandem mass spectrometry (nanoLC-MS/MS) in order to determine the potential players involved in the crocins transport. Overall, our data demonstrated that a mechanism involving mass transport of crocins from crocinoplast to the central vacuole exists in saffron stigmas. This process consists in an increased crocins concentration that triggers their packaging in vesicles, which develop and ultimately merge with the vacuole to deliver crocins inside.

\section{Results}

\subsection{Ultrastructural Characterization of Chromoplast Biogenesis in Saffron}

Six time-points of fresh stigmas were defined: white (Figure 1A-A"), yellow (Figure 1B-B"), orange-yellow (Figure 1C-C"), orange (Figure 1D-D"), red (Figure 1E-E") and red-scarlet (Figure 1F-F"), according to [14], were examined by light and transmission electron microscopy. Pistil structural organization was consistent with that previously reported [11]. The stigmas were formed by several layers of parenchymatic cells, covered by a layer of epidermic cells and two vascular bundles run longitudinally the fundamental tissue. During stigma development, this tissue organization was not altered, but remarkable changes were detected at the subcellular level (Figure $1 \mathrm{~A}^{\prime}-\mathrm{F}^{\prime}$ ).

Overall, cells from earlier developmental stages showed an abundance of organelle-containing cytoplasm, although vacuoles were also present (Figure $1 \mathrm{~A}^{\prime}-\mathrm{C}^{\prime}$ ). In red stigmas at anthesis, the cells showed a large central vacuole occupying almost all the cell volume (Figure $1 \mathrm{~F}^{\prime}$ ). In white stigmas, plastids were already detected. They were typically small, round, and included few developing membranous cisternae and/or starch deposits (Figure 1A"). At the yellow stage, plastids increased in size and presented more starch deposits and membranous tubular or cisternal-like elements in the stroma than in the white stage (Figure 1B"). The transition from the yellow to the orange stage was 
characterized by a reduction in the number and size of starch deposits, while membranous cisternal and tubular elements continued to accumulate (Figure $1 C^{\prime \prime}$ ). At the orange stage, plastids were even larger compared to the previous stages, the starch granules were residual whereas the membranous structures were abundant, forming a polarized network of interconnected tubules and cisternae that occupied an important part of the stroma (Figure 1D").

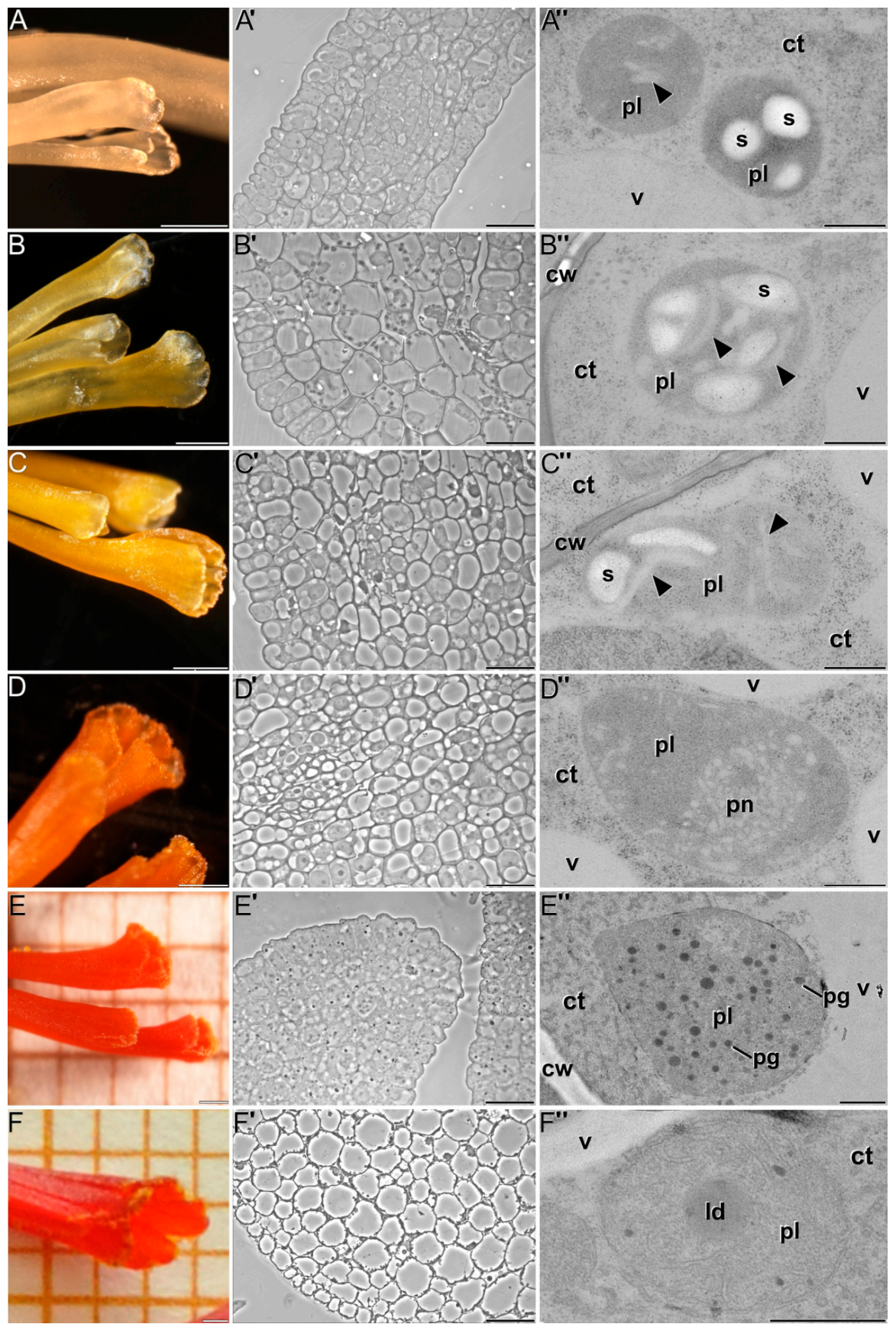

Figure 1. The different stages of saffron stigma development: white (A-A"); yellow (B-B"); orange-yellow $\left(\mathbf{C}-\mathbf{C}^{\prime \prime}\right)$; orange $\left(\mathbf{D}-\mathbf{D}^{\prime \prime}\right)$; red $\left(\mathbf{E}-\mathbf{E}^{\prime \prime}\right)$; and red-scarlet $\left(\mathbf{F}-\mathbf{F}^{\prime \prime}\right)$. A general microscopy overview of stigmas at each stage is shown in $(\mathbf{A}-\mathbf{F}) ;\left(\mathbf{A}^{\prime}-\mathbf{F}^{\prime}\right)$ show display light microscope images of tissue organization at each stage; and $\left(\mathbf{A}^{\prime \prime}-\mathbf{F}^{\prime \prime}\right)$ display electron micrographs of plastids at each stage. Arrowheads point to plastid membranous structures. ct: cytoplasm; cw: cell wall; ld: lipid droplet; pg: plastoglobule; pn: polarized network; pl: plastid; s: starch; v: vacuole. Bars in (A-F): $500 \mu \mathrm{m} ;\left(\mathbf{A}^{\prime}-\mathbf{F}^{\prime}\right)$ : $20 \mu \mathrm{m}$; $\left(\mathbf{A}^{\prime \prime}-\mathbf{F}^{\prime \prime}\right): 500 \mathrm{~nm}$. 
Upon reaching the red stage, some plastids still contained few starch deposits, but they were eventually lost at anthesis. From the red stage (Figure 1E") onwards, the membranous network spanned throughout the entire plastid volume. In addition, plastoglobules of different sizes began to be evident. The membranous network together with the presence of plastoglobules defined the conversion of plastids into chromoplasts, which increased in number and size as red stigmas developed. In addition to these features, we identified the presence of spherical, homogeneously electron dense globules much larger than plastoglobules (Figure $1 \mathrm{~F}^{\prime \prime}$ ) and not detected in the previous stages.

The microscopy studies showed the presence and dynamics of these globules, closely resembling lipid droplets, along the different stages of the red stigma. They continuously increased in size, reaching a maximum diameter of up to $1.5 \mathrm{~nm}$ in the late red stigmas. Interestingly, at this stage, the chromoplasts were usually found close to the central vacuole and even connected to it through their membranes (Figure 2A). In such a connection, numerous images suggested a transference of the large globules from the chromoplast to the vacuole (Figure 2B), leaving an empty space in the chromoplast (asterisk in Figure 2B). In some pictures, the whole chromoplast appeared as if it was digested by the vacuole (Figure 2C). In addition, many of these large globules were found within the vacuole and some of them showed signs of rupture and degradation (Figure 2D), evidencing that once into the vacuole, these large lipid droplets started to break down and release their contents to the vacuolar lumen. In addition, we detected in these same samples the presence of red soluble pigments (Figure 3A) and crystals (Figure 3B) in the vacuole when plasmolyzed cells were examined under the light microscope.
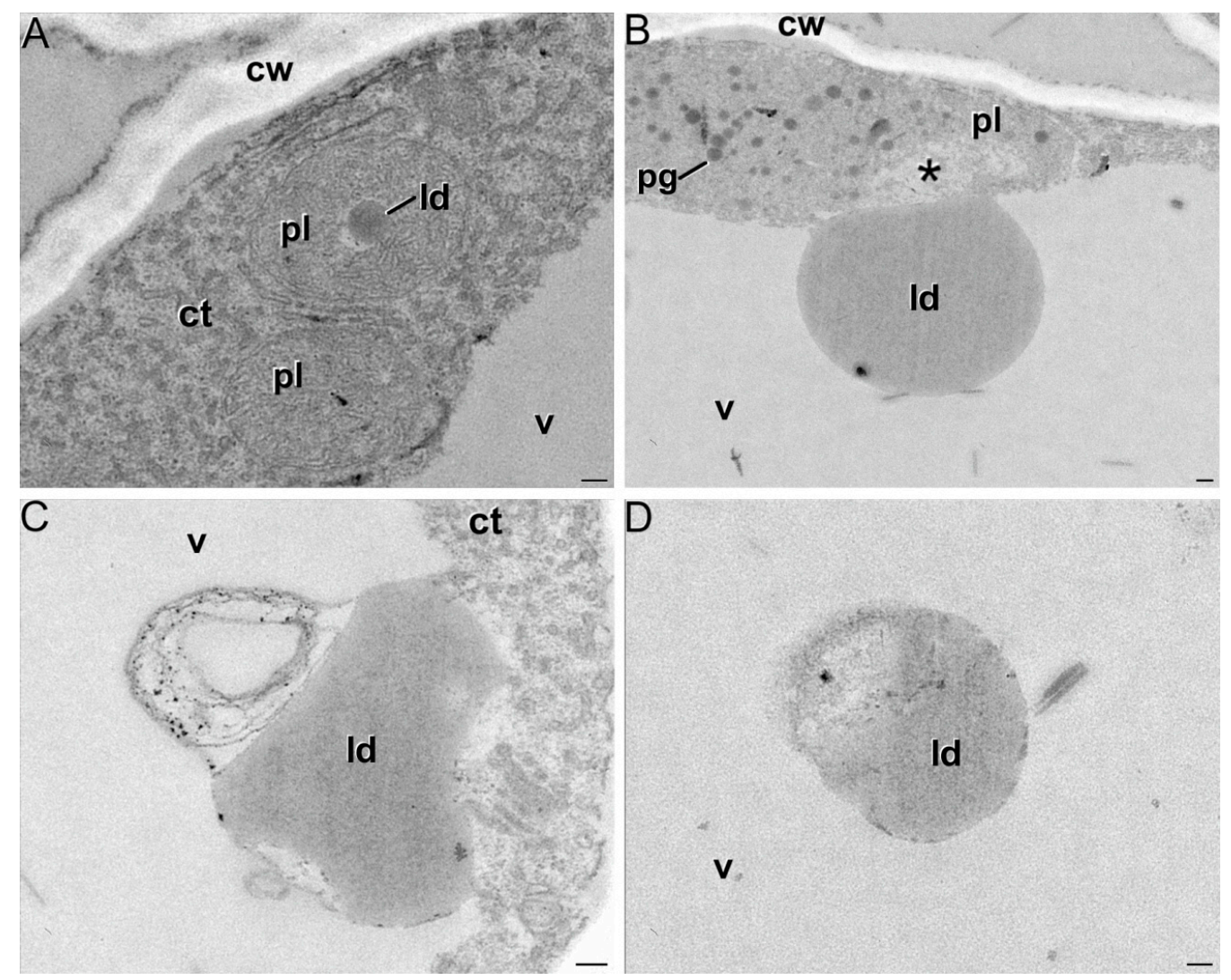

Figure 2. Different stages in lipid droplet transport to the vacuole: (A) chromoplast (pl) with a lipid droplet (ld) within; (B) droplet being transferred to the vacuole (v) and leaving an empty space (asterisk) in the chromoplast; (C) entire chromoplast being degraded while entering the vacuole; and (D) lipid droplet being degraded once in the vacuole; ct: cytoplasm; cw: cell wall; pg: plastoglobule. Bars: $100 \mathrm{~nm}$. 


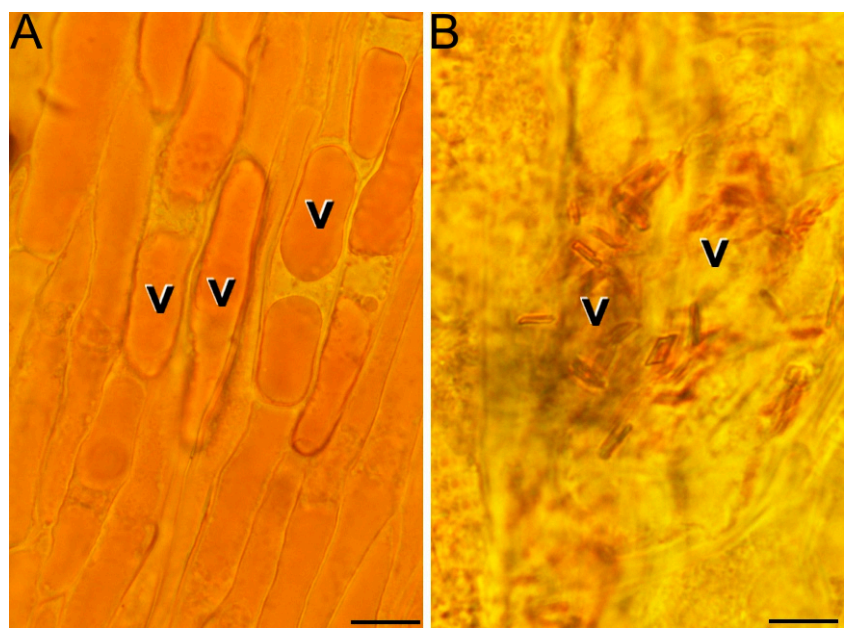

Figure 3. Presence of pigments, both soluble (A) and crystalline (B), in the vacuole (v) of plasmolyzed cells from red stigmas at anthesis. Bars: $20 \mu \mathrm{m}$.

\subsection{Overall Proteomic Analysis}

Four bands (corresponding to the 15\%/30\%, 30\%/40\% 40\%/50\% and 50\%/60\% interfaces, respectively) were collected and chromoplasts recovered as indicated in the Material and Methods Section (Figure 4). Bands from $15 \% / 30 \%$ and $30 \% / 40 \%$ have some degraded membranous-like structures when they were checked under microscopy and were not analyzed. High-Performance Liquid Chromatography with Diode-Array Detection (HPLC-DAD) analysis revealed the presence of crocins only in fractions F1 (band from 50\%/60\%) and F2 (band from 40\%/50\%) (Figure 4). To further check the purity of the chromoplasts banding at the $40 \% / 50 \%$ and $50 \% / 60 \%$ interfaces, the activity of specific marker enzymes was determined and related to the total activity measured in the crude cell homogenate. Since succinate dehydrogenase and catalase activity were detected, mitochondrial and peroxisomal contaminations were present in both fractions, although at a low level (less than 5\%), while no alcohol dehydrogenase activity was found, thus indicating that the chromoplast preparations were free from cytosolic contamination. The comparison between the two fractions revealed that F1 and F2 shared 380 proteins while 338 and 363 were exclusive to F1 and F2 respectively (Figure 5A). Classification of the identified proteins according to MapMan allowed an overview of the abundance of proteins in various functional classes (Figure 5B,C). The function corresponding to the highest number of proteins was TCA/organic acids transformation in both fractions. Proteins associated with photosynthesis and carbon metabolism, electron transport/ATP synthesis, amino acid metabolism, stress and redox, lipid and secondary metabolism, signaling, and transport were also present in relatively high abundance [15-17].

\subsection{Proteins Involved in Isoprenoid Biosynthesis and Accumulation}

For the first time, LC-MS/MS was used as an analytical method for the identification of chromoplasts from saffron stigma at anthesis stage. We produced a proteomic draft, which represents a resource for future studies in saffron and organelle field. Proteomic tools have been recently applied to characterize the proteome of fresh and dried saffron stigmas and style in order to identify saffron from different geographical origins and to detect possible cases of fraud. In this study, 1D-Gel Electrophoresis was carried out and only five proteins have been identified. No differences were found among saffron from different location and the protein profile was quite distinct from the two common adulterants, Carthamus tinctorius and Gardenia jasminoides [18]. Since Crocus sativus has not been sequenced yet, data obtained from proteomes analysis were searched against the Magnoliophyta (2057887 sequences) and Crocus (513 sequences) databases from UniProtKB (available on: http://www.uniprot.org/). Analysis of saffron chromoplasts showed the presence of important enzymes involved in isoprenoid 
pathways as found the presence of the 1-deoxy-D-xylulose 5-phosphate synthase (DXS, Fraction 2) and isoreductoisomerase (DXR, Fractions 1 and 2) enzymes (Table S1). The first committed step in the carotenoid pathway is catalyzed by PSY, resulting in the condensation of two C-20 geranylgeranyl diphosphate (GGPP) molecules to form phytoene [19]. Only Phytoene synthase 2 (CsPSY2) was detected in the proteome of the present study. Phytoene desaturase (PDS) and $\zeta$-carotene desaturase (ZDS) were detected in F1 and F2 (Tables 1 and 2) with PDS having the highest PSMs within all the enzymes of the pathway. 15-cis- $\zeta$-carotene isomerase (Z-ISO) and the carotenoid isomerase (CRTISO) were identified in both fractions (Tables 1 and 2). Both lycopene $\beta$-cyclase CstLcyB1 and CstLcyB2a proteins previously described [6] were present in the two fractions (Table 1, Table 2 and Table S1).
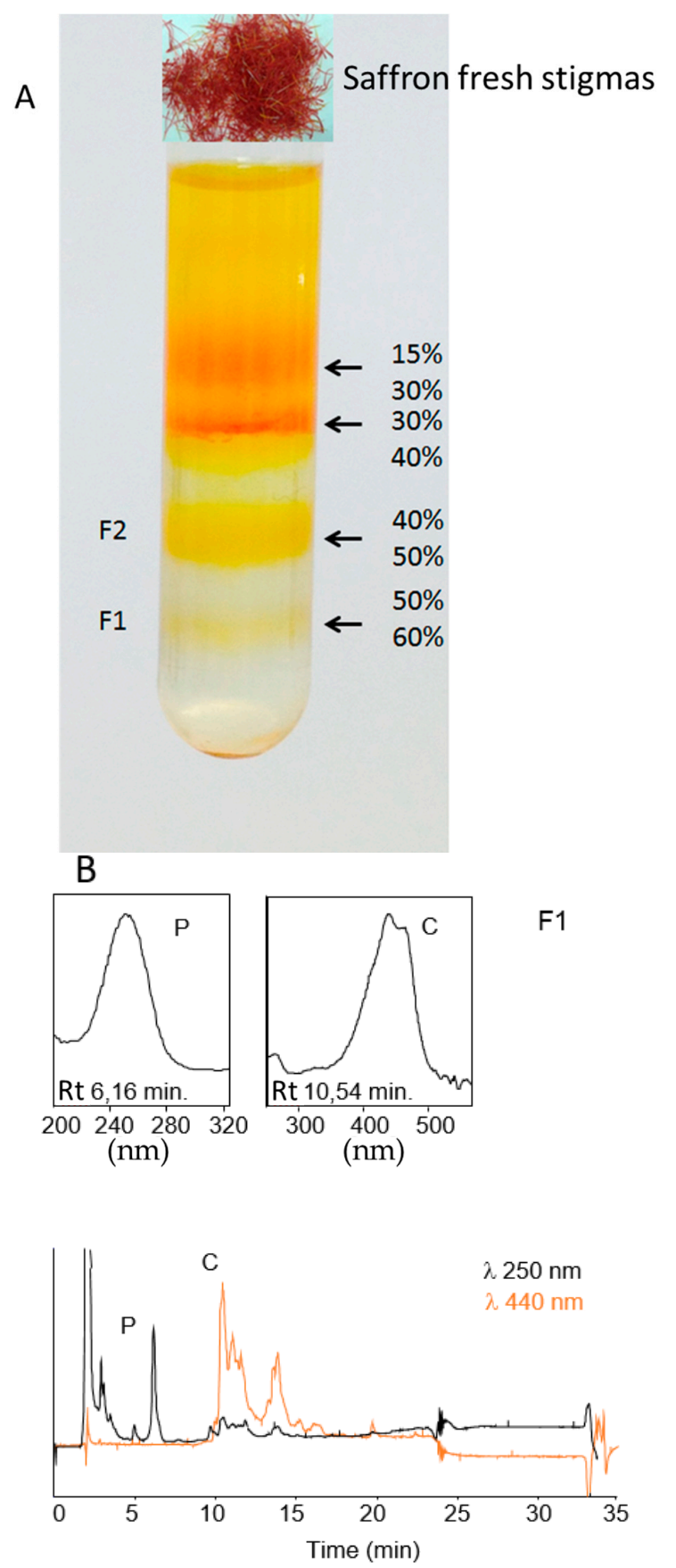

Figure 4. (A) Pattern of bands obtained after sucrose density gradient from saffron fresh stigmas; and (B) HPLC DAD chromatograms showing the presence of crocins in fraction F1. 


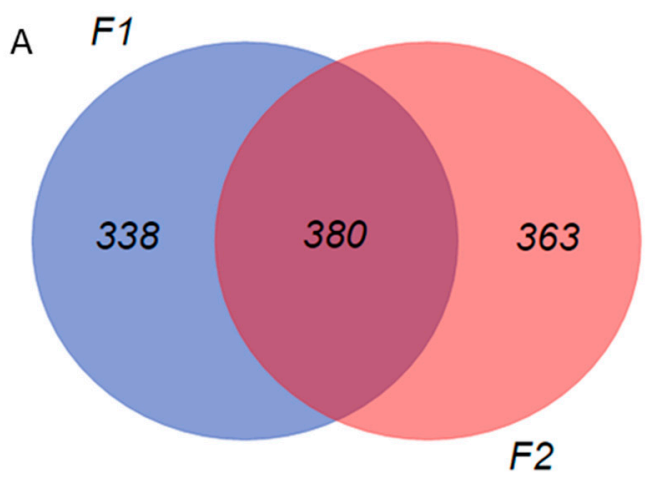

B

F1-50/60\%

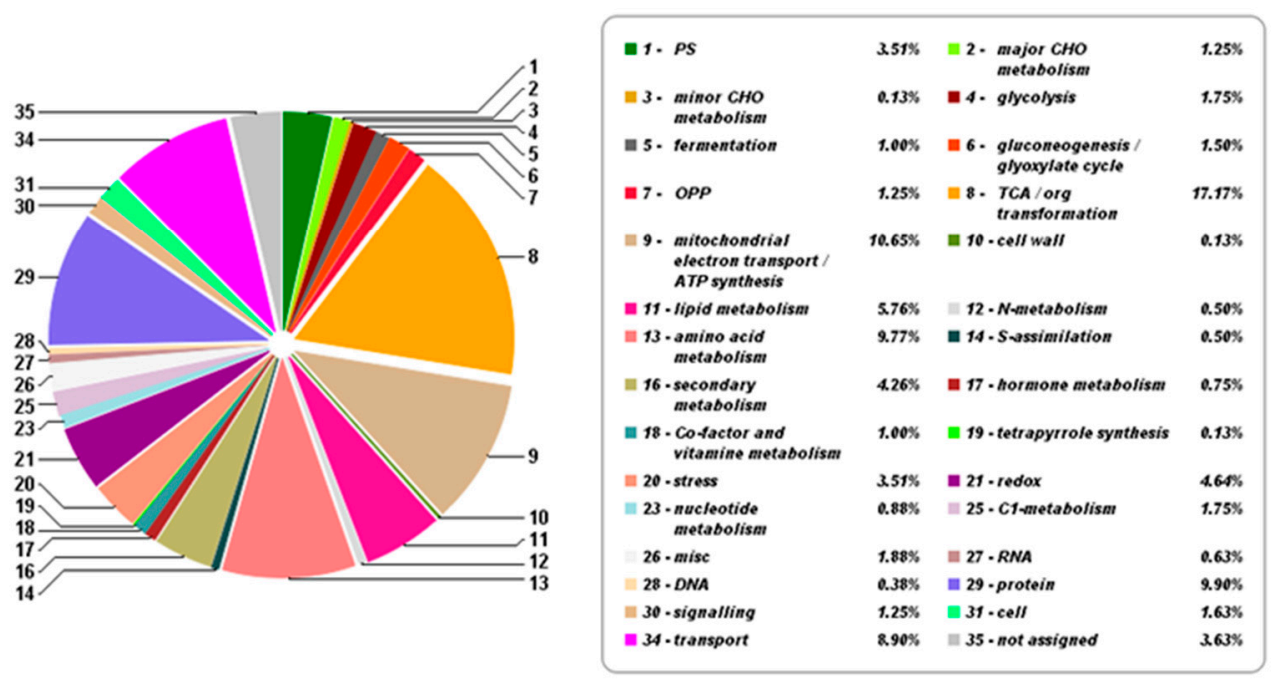

C

F2-40/50\%

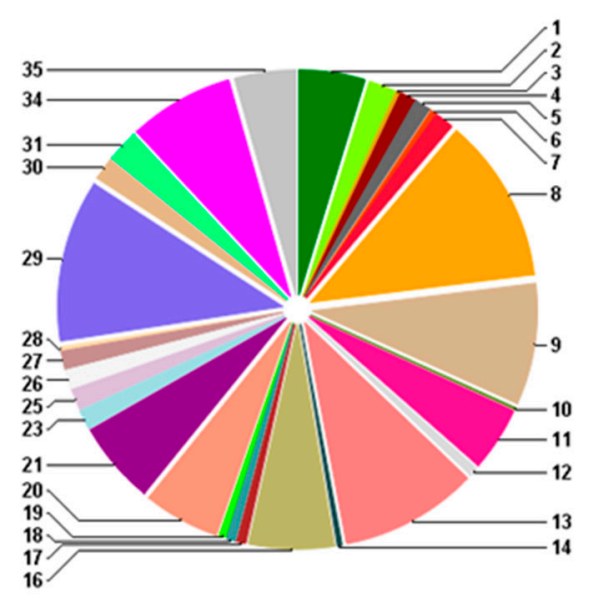

\begin{tabular}{|c|c|c|c|}
\hline$=1 \cdot P S$ & $4.74 \%$ & 2. $\begin{array}{c}\text { major } \mathrm{CHO} \\
\text { metabolism }\end{array}$ & $205 \%$ \\
\hline$=3 \cdot \begin{array}{l}\text { minor } \mathrm{CHO} \\
\text { metabolism }\end{array}$ & $0.22 \%$ & - 4. glycolysis & $1.18 \%$ \\
\hline = 5. fermentation & $1.18 \%$ & $\begin{array}{l}\text { 10. gluconeogenesis / } \\
\text { glyoxylate cycle }\end{array}$ & $0.43 \%$ \\
\hline$=7 \cdot O P P$ & $1.40 \%$ & $\begin{array}{l}=8 \cdot \text { TCA /org } \\
\text { transformation }\end{array}$ & $11.8 \% \%$ \\
\hline $\begin{array}{l}\text { =9- mitochondrial } \\
\text { efectron transport/ } \\
\text { ATP synthesis }\end{array}$ & $2.72 \%$ & =10-cell wall & $0.11 \%$ \\
\hline$=11$ - fipid metabolism & $4.63 \%$ & $12 \cdot$ N-metabolism & $0.65 \%$ \\
\hline $\begin{array}{r}13 \cdot \text { amino acid } \\
\text { metabolism }\end{array}$ & $9.90 \%$ & $=14 \cdot S$ - assintilation & $0.32 \%$ \\
\hline $\begin{array}{c}=16 \cdot \text {-secondary } \\
\text { metabolism }\end{array}$ & $6.14 \%$ & "17 · hormone metabolism & $0.65 \%$ \\
\hline $\begin{array}{l}18 \cdot \text { Co-factor and } \\
\text { vitamine metabolism }\end{array}$ & $0.65 \%$ & = 19 - tetrapyrrole synthesis & $0.5 \% \%$ \\
\hline$\equiv 20$-stress & $5.49 \%$ & $=21 \cdot$ redox & $5.92 \%$ \\
\hline $\begin{array}{l}=23 \cdot \text { mucleotide } \\
\text { metabolism }\end{array}$ & $1.40 \%$ & $=25 \cdot$ C1-metabolism & $1.51 \%$ \\
\hline $26-m i s c$ & $1.29 \%$ & $\equiv 27 \cdot R N A$ & $1.29 \%$ \\
\hline $28 \cdot D N A$ & $0.32 \%$ & $=29 \cdot$ protein & $11.63 \%$ \\
\hline$=30$ - signalling & $1.61 \%$ & $\| 31 \cdot c e l l$ & $226 \%$ \\
\hline$=34$. transport & $7.53 \%$ & $=35 \cdot$ not assigned & $4.41 \%$ \\
\hline
\end{tabular}

Figure 5. (A) Venn diagram obtained after comparison between F1 and F2. Functional category of plastidial proteins identified according to MapMan in: Fraction 1 (B); and Fraction 2 (C). Functional category of plastidial proteins identified from F1 and F2 fractions according to MapMan. 
Table 1. Identification of proteins involved in carotenoid pathway and plastid-lipid-associated proteins, deduced from LC-MS/MS data of fraction F1 from saffron chromoplasts.

\begin{tabular}{|c|c|c|c|c|c|c|c|}
\hline Uniprot ID & Homologous to Predicted Proteins & Score & Cov. $(\%)$ & \# Prot. & \# UP. & \# Pept. & \# PSMs \\
\hline \multicolumn{8}{|c|}{ Carotenoid Pathway } \\
\hline H9MZJ1 & 1-Deoxy-D-xylylose 5-phosphate reductoisomerase & 2.9 & 3.9 & 20 & 1 & 1 & 1 \\
\hline J9XGW7 & 4-Hydroxy-3-methylbut-2-enyl diphosphate reductase & 5.56 & 6.74 & 71 & 1 & 2 & 2 \\
\hline W8SQV6 & Aldehyde dehydrogenase 2-1 & 74.4 & 8.6 & 109 & 1 & 4 & 15 \\
\hline A0A061E1Z5 & Aldehyde dehydrogenase 6B2 & 40.4 & 10.0 & 34 & 3 & 4 & 10 \\
\hline M8AU02 & Aldehyde dehydrogenase family 2 member B4 & 28.0 & 5.7 & 34 & 1 & 4 & 8 \\
\hline A0A0B2PSM8 & Aldehyde dehydrogenase family 2 member B7 & 50.3 & 11.0 & 156 & 2 & 6 & 16 \\
\hline Q9LLR2 & Aldehyde dehydrogenase & 111.3 & 10.1 & 99 & 1 & 3 & 25 \\
\hline A0A075W695 & Carotenoid cleavage dioxygenase 2 & 29.0 & 17.3 & 34 & 2 & 8 & 9 \\
\hline A0A075IEG5 & Carotenoid cleavage dioxygenase 7 & 2.6 & 2.7 & 1 & 1 & 1 & 1 \\
\hline Q2R2A6 & Carotenoid isomerase & 48.2 & 5.6 & 27 & 2 & 3 & 11 \\
\hline B7SNW3 & Chromoplast carotenoid cleavage dioxygenase $4 \mathrm{~b}$ & 11.3 & 7.9 & 5 & 4 & 4 & 4 \\
\hline D2IFC2 & Chromoplast-specific lycopene $\beta$ cyclase OS=Crocus sativus & 80.4 & 13.4 & 1 & 4 & 4 & 18 \\
\hline Q6X1C0 & Crocetin glucosyltransferase 2 & 24.8 & 10.6 & 18 & 4 & 4 & 6 \\
\hline A0Ā0D4D933 & CRTISO & 60.7 & 7.7 & 70 & 1 & 4 & 14 \\
\hline S5VPK3 & Lycopene $\beta$-cyclase & 8.1 & 10.8 & 65 & 1 & 1 & 2 \\
\hline B9S6H4 & Phytoene dehydrogenase & 16.7 & 2.0 & 1 & 1 & 1 & 4 \\
\hline Q84XU1 & Phytoene desaturase & 105.4 & 25.5 & 229 & 10 & 10 & 26 \\
\hline P37273 & Phytoene synthase 2 & 9.9 & 3.5 & 16 & 1 & 1 & 3 \\
\hline C5I849 & Phytoene synthase & 17.0 & 5.0 & 1 & 1 & 1 & 3 \\
\hline A0A075M6P3 & UDP-glucosyltransferase UGT85U1 & 3.7 & 4.0 & 2 & 1 & 1 & 1 \\
\hline I0AXV3 & $\zeta$-Carotene desaturase & 62.5 & 15.5 & 113 & 2 & 7 & 15 \\
\hline D7TUM8 & $\zeta$-Carotene desaturase & 55.7 & 11.6 & 88 & 1 & 5 & 14 \\
\hline \multicolumn{8}{|c|}{ Plastid-Lipid-Associated Proteins } \\
\hline K7UIX3 & Plastid-lipid-associated protein 2 & 15.1 & 9.5 & 19 & 1 & 2 & 4 \\
\hline A0A0B2RM96 & Plastid-lipid-associated protein & 39.0 & 7.8 & 24 & 1 & 2 & 9 \\
\hline A9CSJ8 & Putative plastid lipid-associated protein & 42.7 & 12.2 & 28 & 0 & 2 & 10 \\
\hline
\end{tabular}

Proteins were searched against the Magnoliophyta and Crocus databases of Uniprot. Proteins are ordered alphabetically within each functional group, and the hits with maximal scores and number of PSMs in each category are highlighted in bold. The hits identified as homologous to Crocus sativus proteins are underlined. Cov. $=$ coverage; \# Prot. = number of proteins; \# UP. = number of unique peptides; \# Pept. = number of peptides; \# PSMs. = number of peptide spectrum matches. 
Table 2. Identification of proteins involved in carotenoid pathway and plastid-lipid-associated proteins, deduced from LC-MS/MS data of fraction F2 from saffron chromoplasts.

\begin{tabular}{|c|c|c|c|c|c|c|c|}
\hline Uniprot ID & Homologous to Predicted Proteins & Score & Cov. $(\%)$ & \# Prot. & \# UP. & \# Pept. & \# PSMs. \\
\hline \multicolumn{8}{|c|}{ Carotenoid Pathway } \\
\hline A0A059VDA9 & 1-Deoxy-D-xylulose 5-phosphate reductoisomerase & 39.0 & 24.3 & 95 & 1 & 7 & 10 \\
\hline G8FL07 & 1-Deoxy-D-xylulose 5-phosphate reductoisomerase & 30.0 & 13.6 & 18 & 1 & 5 & 8 \\
\hline A0A075EAM0 & 1-Deoxy-D-xylulose 5-phosphate reductoisomerase & 35.6 & 16.0 & 18 & 1 & 4 & 9 \\
\hline B9RB24 & 1-Deoxy-D-xylulose 5-phosphate reductoisomerase, chloroplast & 15.1 & 4.8 & 3 & 1 & 2 & 4 \\
\hline W6HY22 & Chloroplast 1-deoxy-D-xylulose-5-phosphate reductoisomerase & 49.3 & 24.4 & 133 & 1 & 7 & 13 \\
\hline C7U110 & 1-Deoxy-D-xylulose-5-phosphate synthase 1 & 10.8 & 4.6 & 99 & 1 & 3 & 4 \\
\hline O22567 & 1-Deoxy-D-xylulose-5-phosphate synthase 1 , chloroplastic & 11.1 & 4.6 & 94 & 1 & 3 & 4 \\
\hline O81014 & 4-Diphosphocytidyl-2-C-methyl-D-erythritol kinase, chloroplastic & 3.9 & 6.75 & 10 & 1 & 1 & 1 \\
\hline P93841 & 4-Diphosphocytidyl-2-C-methyl-D-erythritol kinase, chloroplastic/chromoplastic & 2.8 & 4.81 & 6 & 1 & 1 & 1 \\
\hline J9XH53 & Putative 4-diphosphocytidyl-2-C-methyl-D-erythritol kinase & 3.8 & 5.24 & 1 & 1 & 1 & 1 \\
\hline D2D5E3 & (E)-4-hydroxy-3-methylbut-2-enyl diphosphate synthase & 55.3 & 13.78 & 53 & 1 & 7 & 15 \\
\hline W8SNM0 & 4-Hydroxy-3-methylbut-2-en-1-yl diphosphate synthase protein & 54.2 & 10.95 & 72 & 1 & 7 & 15 \\
\hline A0A089G093 & 1-Hydroxy-2-methyl-2-(E)-butenyl-4-diphosphate reductase & 46.3 & 13.61 & 76 & 2 & 6 & 12 \\
\hline W5GTY8 & 2-C-Methyl-D-erythritol 2,4-Cyclodiphosphate synthase & 8.2 & 18.01 & 80 & 3 & 3 & 3 \\
\hline D2CFT5 & Hydroxymethylbutenyl diphosphate reductase & 22.1 & 12.31 & 92 & 2 & 6 & 6 \\
\hline Q9SLG2 & GGPP4_ARATH Geranylgeranyl pyrophosphate synthase 4 & 3.4 & 4.64 & 1 & 1 & 1 & 1 \\
\hline A0A097PPW4 & 15-cis-Ц-carotene isomerase & 7.1 & 4.5 & 1 & 1 & 1 & 2 \\
\hline A0A061E1Z5 & Aldehyde dehydrogenase $6 \mathrm{~B} 2$ & 40.4 & 11.3 & 36 & 2 & 4 & 8 \\
\hline Q9LRI6 & Aldehyde dehydrogenase ALDH2a & 32.9 & 6.0 & 22 & 1 & 3 & 9 \\
\hline M8AU02 & Aldehyde dehydrogenase family 2 member B4 & 51.2 & 5.7 & 27 & 1 & 4 & 14 \\
\hline W9RMT5 & Aldehyde dehydrogenase family 2 member & 34.1 & 6.4 & 91 & 1 & 3 & 9 \\
\hline A0A059BY89 & Aldehyde dehydrogenase & 13.2 & 7.7 & 85 & 3 & 3 & 4 \\
\hline I1QYB5 & Aldehyde dehydrogenase & 4.2 & 2.3 & 4 & 1 & 1 & 1 \\
\hline Q8VXP2 & $\beta$-Carotene hydroxylase & 2.5 & 4.9 & 1 & 1 & 1 & 1 \\
\hline A0A075W695 & Carotenoid cleavage dioxygenase 2 & 72.6 & 23.7 & 1 & 4 & 12 & 18 \\
\hline B7SNW1 & Carotenoid cleavage dioxygenase 2 & 58.6 & 20.8 & 1 & 2 & 10 & 15 \\
\hline V5K7G6 & Carotenoid isomerase (Fragment) & 152.3 & 7.7 & 44 & 1 & 3 & 34 \\
\hline A0A072VJ38 & Carotenoid isomerase & 20.7 & 3.7 & 20 & 1 & 2 & 6 \\
\hline B7SNW3 & Chromoplast carotenoid cleavage dioxygenase $4 b$ & 25.9 & 14.2 & 6 & 6 & 6 & 7 \\
\hline D2IFC2 & Chromoplast-specific lycopene $\beta$ cyclase & 128.5 & 22.0 & 1 & 7 & 7 & 29 \\
\hline Q6X1C0 & Crocetin glucosyltransferase 2 & 17.8 & 10.6 & 18 & 4 & 4 & 5 \\
\hline M7ZM48 & Cytochrome P450 97B2, chloroplastic & 3.34 & 3.81 & 16 & 1 & 1 & 1 \\
\hline F1BPW8 & Lycopene $\beta$-cyclase & 2.9 & 1.8 & 6 & 1 & 1 & 1 \\
\hline
\end{tabular}


Table 2. Cont.

\begin{tabular}{|c|c|c|c|c|c|c|c|}
\hline Uniprot ID & Homologous to Predicted Proteins & Score & Cov. $(\%)$ & \# Prot. & \# UP. & \# Pept. & \# PSMs. \\
\hline S5VPK3 & Lycopene $\beta$-cyclase & 19.1 & 10.8 & 65 & 1 & 1 & 5 \\
\hline K9N4H5 & Mitochondrial aldehyde dehydrogenase 2B8 & 68.2 & 7.8 & 155 & 1 & 5 & 20 \\
\hline A0A072TS23 & NAD-dependent aldehyde dehydrogenase family protein & 28.4 & 5.5 & 102 & 1 & 3 & 8 \\
\hline Q84XU1 & Phytoene desaturase & 285.3 & 48.0 & 242 & 17 & 17 & 68 \\
\hline I1U6I7 & $\overline{\text { Phytoene synthase }}$ & 3.6 & 6 & 4 & 1 & 1 & 1 \\
\hline A0A097PKY8 & Phytoene synthase & 12.8 & 6.7 & 195 & 1 & 2 & 4 \\
\hline C5I849 & Phytoene synthase protein & 33.8 & 8.3 & 138 & 1 & 2 & 7 \\
\hline Q52QW5 & Phytoene synthase, chloroplastic & 35.2 & 5.8 & 153 & 1 & 2 & 10 \\
\hline А0A $075 \mathrm{M} 6 \mathrm{P} 3$ & UDP-glucosyltransferase & 19.7 & 4.0 & 2 & 1 & 1 & 5 \\
\hline I7H187 & $\zeta$-Carotene desaturase & 21.6 & 9.3 & 1 & 1 & 2 & 5 \\
\hline I0AXV3 & $\zeta$-Carotene desaturase & 139.2 & 21.8 & 106 & 5 & 11 & 34 \\
\hline C3VEQ0 & $\zeta$-Carotene desaturase, chloroplastic/chromoplastic & 63.0 & 12.6 & 23 & 2 & 6 & 16 \\
\hline \multicolumn{8}{|c|}{ Plastid-Lipid-Associated Proteins } \\
\hline O99019 & Chromoplast-specific carotenoid-associated protein & 12.3 & 10.4 & 1 & 1 & 1 & 3 \\
\hline I1MFL4 & Chromoplast-specific carotenoid-associated protein & 82.8 & 7.8 & 24 & 2 & 2 & 19 \\
\hline R9TH24 & Chromoplast-specific carotenoid-associated protein & 19.2 & 11.2 & 1 & 2 & 2 & 4 \\
\hline Q8S9M1-6 & Isoform 6 of Probable plastid-lipid-associated protein 13 , chloroplastic & 2.4 & 5.7 & 21 & 1 & 1 & 1 \\
\hline A6XBI6 & Plastid fibrillin 2 & 7.1 & 4.4 & 7 & 1 & 1 & 2 \\
\hline K7UIX3 & Plastid-lipid-associated protein 2 & 14.7 & 9.5 & 19 & 2 & 2 & 4 \\
\hline A0A075F1U0 & Constitutive plastid-lipid associated protein & 16.5 & 28.9 & 48 & 2 & 3 & 5 \\
\hline K7UIX3 & Plastid-lipid-associated protein 2 & 14.7 & 9.5 & 19 & 2 & 2 & 4 \\
\hline
\end{tabular}

Proteins were searched against the Magnoliophyta and Crocus databases of Uniprot. Proteins are ordered alphabetically within each functional group, and the hits with maximal scores and number of PSMs in each category are highlighted in bold. The hits identified as homologous to Crocus sativus proteins are underlined. Cov $=$ coverage. \# Prot $=$ number of proteins. \# UP = number of unique peptides. \# Pept = number of peptides. \# PSM s= number of peptide spectrum matches. 
$\beta$-carotene hydroxylase $\mathrm{CsBCH} 1$ and $\mathrm{CsBCH} 2$ described for saffron were not found in $\mathrm{F} 1$ and only CsBCH1 was detected in fraction F2 (Table 2). We could not find any of the cytochrome P450 enzymes CYP97A3 or CYP97C1 member in the saffron proteome but, interestingly, a CYP97B2 enzyme, previously reported in Arabidopsis to be involved in xanthophyll synthesis [20], was found. All the Carotenoid cleavage dioxygenase enzymes (CCDs) were detected in the analyzed fractions with the exception of CCD8, expressed at low levels in saffron stigma [21], and CCD1 having a cytoplasmic location [14]. CCD2, the key enzyme in crocetin formation [9], is a plastidic enzyme [8] and was found in both fractions (Table 1). Similarly, also CCD4b, another plastid-localized enzyme, playing a key role in pollinator attraction [14], was present in both fractions (Table 1). The last carotenoid dioxygenase identified in the saffron proteome was CCD7. This enzyme, together with CCD8, displays a plastid distinct localization and is involved in strigolactone biosynthesis [22].

Other enzymes detected in the saffron proteome and involved in the apocarotenoid pathway were aldehyde dehydrogenases (ADHs) and UDP-dependent glycosyltransferases (UGTs). In addition to carotenoid metabolism, we found several proteins associated to the synthesis of other isoprenoids: tocochromanols and quinones (all present in Fraction 2).

\subsection{Proteins of Interest in Sequestration and Related to Chromoplast Replication and Remodeling}

Fibrillin and fibrillin homologs, known to be the main components of carotenoid-lipoprotein substructures, were identified (Table 2). Another fundamental player in carotenoid accumulation is the Or gene [23], which is not directly involved in carotenoid biosynthesis at transcript level, but can regulate PSY abundance at post-transcriptional level [24]. Within saffron proteome, several Or homologs were identified in F2.

Replication of chromoplasts is occasionally observed, such as in Forsythia suspensa petals [25] and pepper fruits [26]. Several homologs of the Plastid-dividing ring protein 3 and of the FtsZ proteins (Table S1) involved in this mechanism were detected. In addition, we found two members of the chloroplast inner envelope proteins (CIEPs) [27], as well the protein Chloroplast J-like domain 1, which affects plastid lipid composition and was shown to interact with CIEPs in the frame of the replication process [28].

\subsection{Gene Expression Analysis of Genes Involved in Key Processes of Crocins Metabolism}

The expression data of carotenogenic and sequestration genes detected in the chromoplast proteome, throughout the stigma development, are listed in Table 3 and Figure S1. The two master genes of the MEP pathway, DXS1 and DXR, exhibited their highest peak of expression at anthesis stage. All the carotenogenic genes were expressed in all the developmental time-points except for geranylgeranyl phyrophosphate synthase (CsGGPS), CsCCD7, CsCCD4b, and CstLcyB1, whose transcripts were absent in one or more stages.

$\mathrm{ADH}$ activity is needed to catalyze the oxidation of the crocetin dialdehyde to crocetin; for this reason, we looked for ADHs in saffron chromoplasts, and the corresponding genes were identified in the transcriptome, thus allowing the comparison of these sequences with that previously characterized and recognizing apocarotenoids as substrates [29-31]. Overall, 12 different peptides were detected in the proteome analyses, and further utilized for the identification of the corresponding encoding gene sequences in the transcriptomes. Five different ADHs, ADHComp11367 (accession number KU577907) (Q9LLR2, W8SQV6 and M8AU02), ADHComp3898 (accession number KU577905) (A0A061E1Z5, A0A0B2PSM8, Q8RVW2 and W9RMTS), ADHComp54788 (accession number KU577904) (A0A059BY89 and I1QYB5), ADHComp20158 (accession number KU577906) (K9N4H5) and ADHComp2946 (accession number KU577903) (A0A072TS23 and Q9LRI6), were identified. Phylogenetic analyses revealed that one $\mathrm{ADH}$ ( $A D H C o m p 54788)$ was closely related to $c a r D$, involved in the conversion of $\beta$-apo-4'-carotenal in $\beta$-apo- $4^{\prime}$-carotenol [30], and showed its highest expression levels at anthesis, while the four others ADHs were more closely related to retinal aldehyde dehydrogenases [31,32], 
being ADHComp11367 and ADHComp2946 with the highest expression level at anthesis stage, whereas ADHComp3898 and ADHComp20158 at orange and white stages, respectively (Figure S2).

The action of glucosyltransferases is responsible for the conversion of crocetin into crocins. We investigated the expression of the two UGTs identified in our proteome analyses. Transcripts for UDP-glucosyltransferase UGT85U1 and CsUGT2 were detected from white stage, with the highest peak of expression at anthesis and red stages, respectively (Table 3).

Three different fibrillin-like proteins were detected after manual curation of the sequences; PF2 and PLAP13 showed the same pattern of expression, with a high level at the orange stage, while PLAP2 was mostly up-regulated at the red stage (Table 3).

Table 3. Transcript levels of genes involved in carotenoid pathway, and Plastid-lipid-associated proteins, at five different stages of stigma development. For more details, see materials and methods.

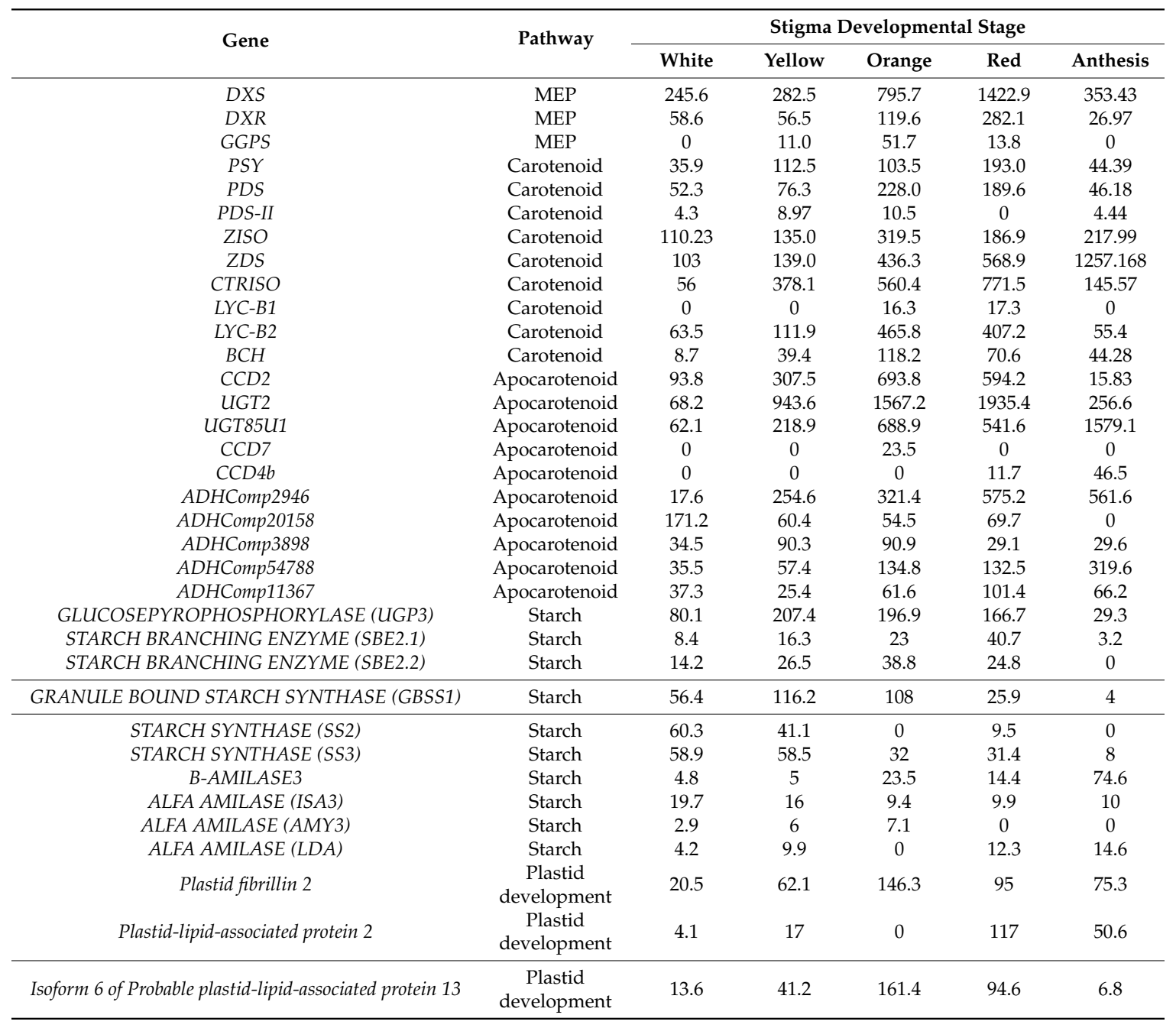

2.6. Gene Expression Analyses of Starch Metabolism Genes: The Carbohydrate Supply for Apocarotenoids Biosynthesis

In addition to carotenoid/transport genes, and due to the evidence by electron microscopy of relevant amount of starch in the cell plastids, we also checked the levels of some genes related to starch metabolism. The expression of glucose-pyrophosphorylase (UGP3), starch branching enzymes (SBE2.1/2.2), granule bound starch synthase (GBSS1) and starch synthase (SS2/3) were up-regulated during the earlier stages, reaching a maximum of expression during the yellow and orange stages, where the largest amounts of amyloplasts were detected, and then started to decline at the red stage. In contrast, the expression of amylase enzymes was down-regulated during the earlier stages 
and reached the highest expression during the anthesis stage, where no amyloplasts were observed (Table 3). All these results agreed with the gradual degradation of starch deposits observed during the stigma development.

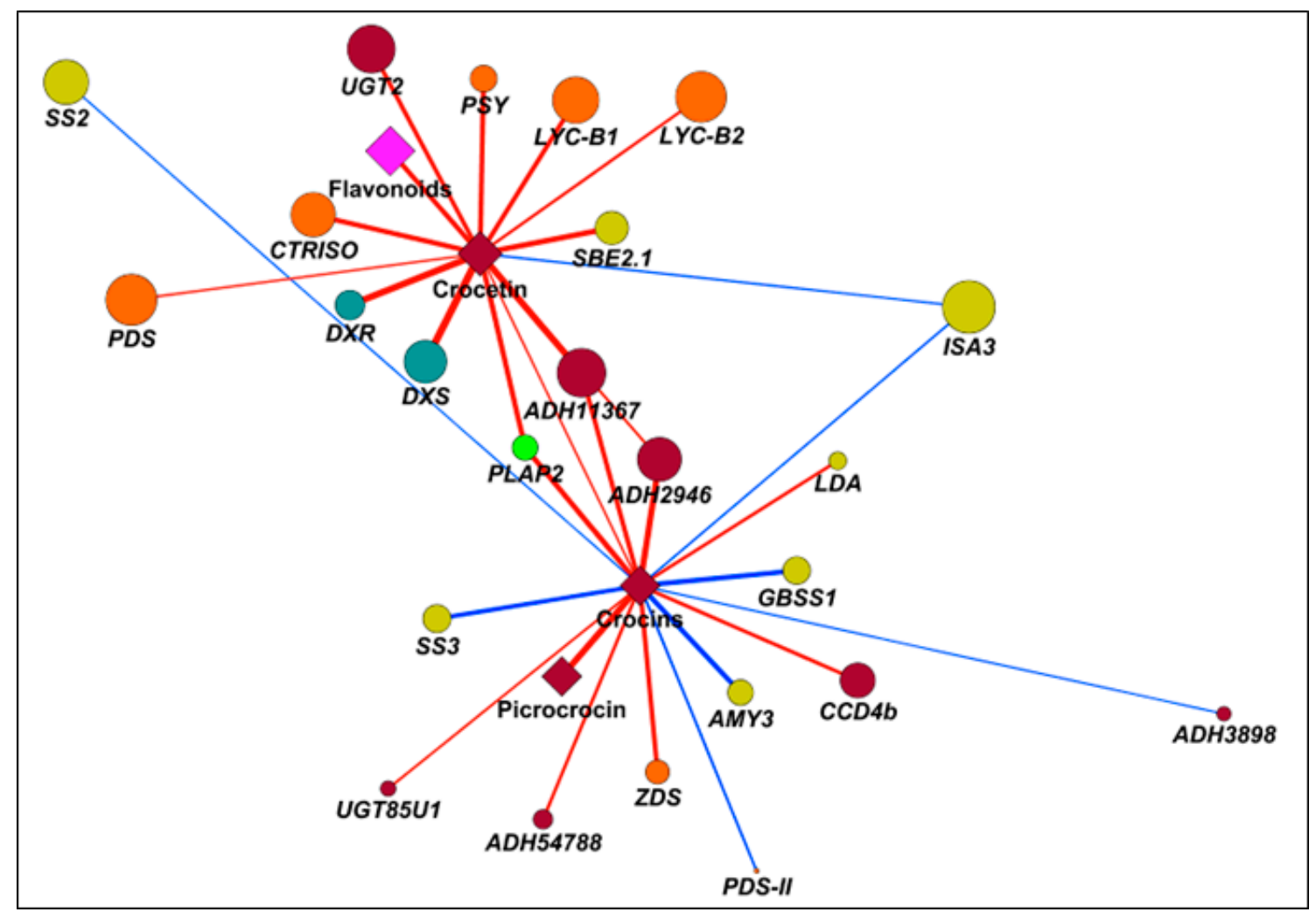

Figure 6. Correlation network of chromoplast genes/metabolites, involved in saffron apocarotenoid synthesis and transport. Genes and metabolites are represented as rounds and diamonds. Different colors identify genes/metabolites involved in MEP (turquoise), carotenoid (orange), apocarotenoid (burgundy), plastid development (green), and starch (yellow) biosynthesis. Blue and red edges refer, respectively, to negative and positive correlations; only correlations $>|0.65|$ are shown. Edge width and node size were drawn according, respectively, the Pearson correlation coefficient $(|p|)$ and the node strength (ns). Edge length was inversely proportional to $|p|$.

\subsection{Correlation Analyses to Identify Candidate Genes Involved in Apocarotenoid Production}

To unravel regulative mechanisms underlying apocarotenoid accumulation in saffron stigma, we exploited correlation analyses on a set of variables including crocetin, crocins and picrocrocin, as well transcripts of carotenoid/apocarotenoid biosynthesis, plastid development and starch metabolism. Symmetric correlation matrix allowed investigation in the relationships within elements of different or of the same pathway (Figure S3). Overall, MEP/carotenoid transcripts, together with CCD2 and UGT2 but except for PDS-II and ZDS, exhibited a very high extent of positive correlations. Notably, the same genes were also correlated with the same sign towards a series of transcripts associated to plastid transformation (PF2, PLAP2, and PLAP13) and starch synthesis (UGP3, SBE2.1, and SBE2.2). Conversely, a second group of genes in the starch metabolism under study (synthetic: SS2 and SS3; catabolic: $B A M 3, I S A 3, A M Y 3$, and $L D A$ ) displayed an area of general negative correlation with respect to most of the other transcripts analyzed. In the present study, we used correlation networks to highlight transcripts positively or negatively correlated with crocetin and crocins (Figure 6, Figures S4 and S5, Table S2). Crocetin only displayed positive correlations, except for ISA3, particularly yielded towards MEP (DXS and DXR) and carotenoid genes (PSY, CRTISO, and LYC-B1/B2), indicating a tight 
up-stream regulation exerted by isoprenoid metabolism on apocarotenoid synthesis. Interestingly, UGT2, known to utilize crocetin as substrate to produce crocins, also showed a significant positive correlation (0.81), and could be considered a positive control. Conversely, crocins did not share relevant correlations with early MEP/carotenoid genes, except for ZDS (positive, 0.81 ) and PDS-II (negative, -0.70 ), but were basically characterized by a series of Pearson coefficients $>|0.65|$ : positive towards a carotenoid dioxygenase $(C C D 4 b, 0.77)$, one aldehyde dehydrogenases (ADH54788, 0.75) and UGT85U1 (0.70); and negative in relation to a series of starch-related genes, ranging from SS2 $(-0.66)$ to $A M Y 3(-0.84)$. These data suggested that crocins synthesis in saffron stigma is subjected to a regulative process, acting at chromoplast development and transformation levels, rather than at carotenoid biosynthetic time. We explored correlation analysis to reveal transcript/s coding for $\mathrm{ADH}$ activities, and responsible for the conversion of crocetin dialdehyde into crocetin. In this context, correlation networks highlighted two potential ADHs highly correlated with crocetin: ADH2946 (0.71) and ADH11367 (0.94). With the same objective, we exploited the Pearson squared distance algorithm in a Hierarchical Clustering (HCL) analysis (Figure 7) which confirmed the high level of relationship between crocetin and $A D H 2946 / A D H 11367$, as well evidenced the presence of a third candidate (ADH54788) with an expression pattern like crocetin.
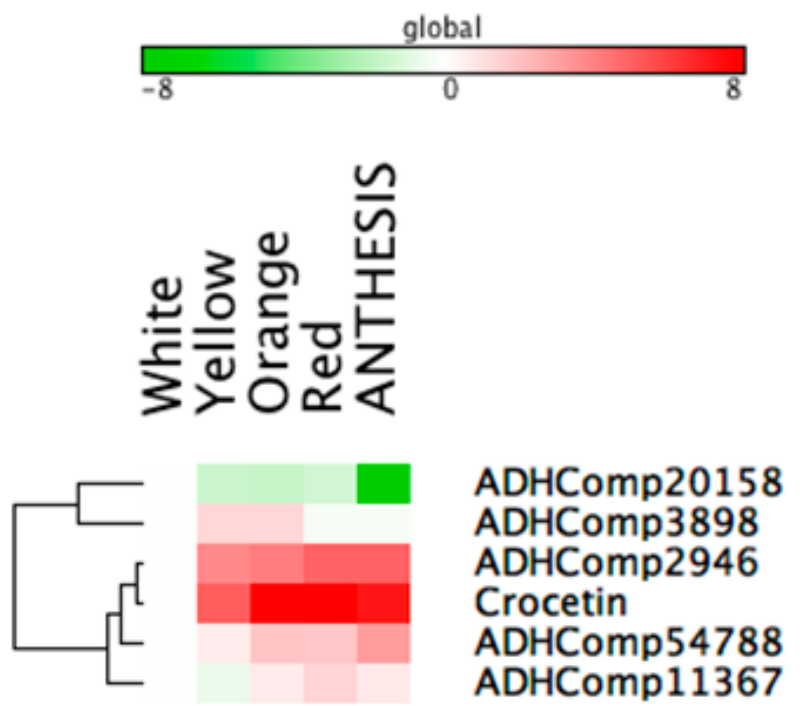

Figure 7. Hierarchical clustering (HCL) of crocetin and aldehyde dehydrogenase (ADH) found in the saffron proteome. Green and red squares represent the values of log2-transformed relative data with respect to the white stage according to the color scale shown. Hierarchical clustering was calculated on rows, applying the Pearson correlation coefficient with the average linkage algorithm.

\section{Discussion}

Variations, at the cytological level, occurring along with the massive synthesis and accumulation of apocarotenoids, and especially the differentiation and evolution of chromoplasts throughout the development of saffron stigmas, have hardly been studied. In the present work, we studied the process of chromoplast differentiation in saffron during stigma maturation, together with the analyses of gene expression and proteomic profiling, in order to better understand the processes taking place in the chromoplasts at different stages of synthesis and accumulation of crocetin and crocin metabolites. In addition, we attempted to provide new insights into the possible transport mechanisms implicated in the release of these apocarotenoids into the central vacuole.

Protein profiling of the chromoplast revealed that the major metabolic pathways were associated to carbohydrate, amino acid, lipid and carotenoid metabolism, as well to protein regulation and transport, and oxidative stress. A number of Calvin cycle proteins were detected in saffron chromoplasts. 
The persistence of a Calvin cycle and oxidative pentose phosphate pathway proteins (i.e., transketolase) is thought to provide intermediates for glycolysis and a main source of reducing power for various processes, respectively, in chromoplasts. These proteins have been detected in several chromoplasts analyzed [33]. In addition, various glycolysis enzymes were observed, suggesting an active metabolism in chromoplasts to generate energy and precursors for the synthesis of metabolites. Enzymes involved in fatty acid metabolism and amino acid as well as many components involved in maintaining cell redox homeostasis, were also found and confirm the chromoplast capacity in relation to lipid synthesis, which could be also responsible for the massive generation of vesicles, as well to chromoplast protection, by regulating redox status and reactive oxygen species (ROS).

The analysis of chromoplasts from carotenoid enriched tissues of saffron stigma identified several MEP and early carotenoid pathway enzyme proteins. Correlation analysis showed that crocetin synthesis is highly dependent on carotenoid pathway, while the process of crocin accumulation looked more related to the conversion of the amyloplasts in chromoplasts. Despite of the main function of chromoplasts which is the accumulation of pigments, a high number of compounds are synthetized in these structures such as sugars, starches, lipids, aromatic compounds, vitamins and hormones [34,35]. Chromoplasts, unlike green plastids, are unable to synthesize all the metabolites necessary for these processes and, thus, need often to import them by the cytosol. To sustain the biosynthetic activities, sugars and energy (ATP) are required [13]. Sugars can be imported from the cytosol [36], or can be taken from starch degradation [13,37]; [34]. Our results indicate that in the earlier stages of style development from white to yellow-orange an accumulation of membranous sinks and starch granules occur, which are more abundant in the yellow stage, decreasing hereinafter. However, these structures are present in all stages excluding the anthesis stage.

Carotenoid accumulation in chromoplast has been attributed to a variety of factors, among them, important roles are played by specific proteins called chromoplast-specific carotenoid-associated proteins [38] and the Orange (Or) protein [39]. Eight proteins belonging to the fibrillin/plastid lipid associated protein family were detected in saffron chromoplasts and were developmentally regulated with carotenoid content. These proteins are the main component of carotenoid lipoprotein sequestration and are implicated in the over-production of pigments due to a sink effect. Transgenic tomato plants expressing pepper fibrillin were found to accumulate this protein during fruit ripening from an early mature green stage, and having a two-fold increase in carotenoids content and derivatives [40]. We found a very strong correlation between PLAP2 and crocetin and crocins, suggesting the involvement of this protein in the assembly of these apocarotenoids in macromolecular structures of the chromoplasts. In addition, these proteins have been reported to be involved in abiotic stress responses [41]; in this context, their accumulation in saffron chromoplast could be interpreted as a further mechanism of organelle protection.

Chromoplasts are organelles with a highly active metabolic system accumulating different kinds of carotenoid pigments in different types of structures but the relationship between the structures and the nature of the chemical compounds contained inside these vesicles is not always clear. In many chromoplasts, a special membrane system, called system of internal membranes of chromoplasts (MICs), is formed de novo by invagination of the inner membrane of the plastid where carotenogenic enzymes are found and biosynthesis of carotenoids takes place [42,43]. This hypothesis is supported by the presence, in the saffron proteome, of proteins as CIEPs Chloroplast J-like domain 1, which can contribute to the generation of MICs, vesicles and to plastid division. Taken together our results suggest that crocetin synthesis happen in the saffron chromoplasts MICs, and mainly from the orange stage onwards. Glycosylation of crocetin should happen also in the chromoplast, due to the plastidial localization of CsUGT2.

From the generally polarized MICs, the formation of large globules resembling lipid droplets, and much larger than plastoglobules, occur from the red stage onwards. Chromoplasts containing these large globules (hereafter named crocinoplast) are usually close or connected to the vacuole, suggesting that these lipids droplet-like structures could contain saffron crocins. Our model consists of 
a direct transference from the polarized end of the chromoplast, where the formation of crocinoplasts containing crocins occurs, (Figures 2 and 8) to the vacuole. They might originate from many smaller vesicle-like structures that gradually fuse together. Direct apocarotenoid transport from chromoplast to vacuole was observed in Bixa orellana [44] and fusion between carotenoid rich lipid drops and the vacuole has been described in aging spores of Puccinia distincta [45]. Our observations suggested that, in some cases, the whole chromoplast is digested by the vacuole. Processes of macroautophagy, whereby plastids were introduced into lytic vacuoles to be digested have been previously described in Brassica napus embryogenic microspores [46].

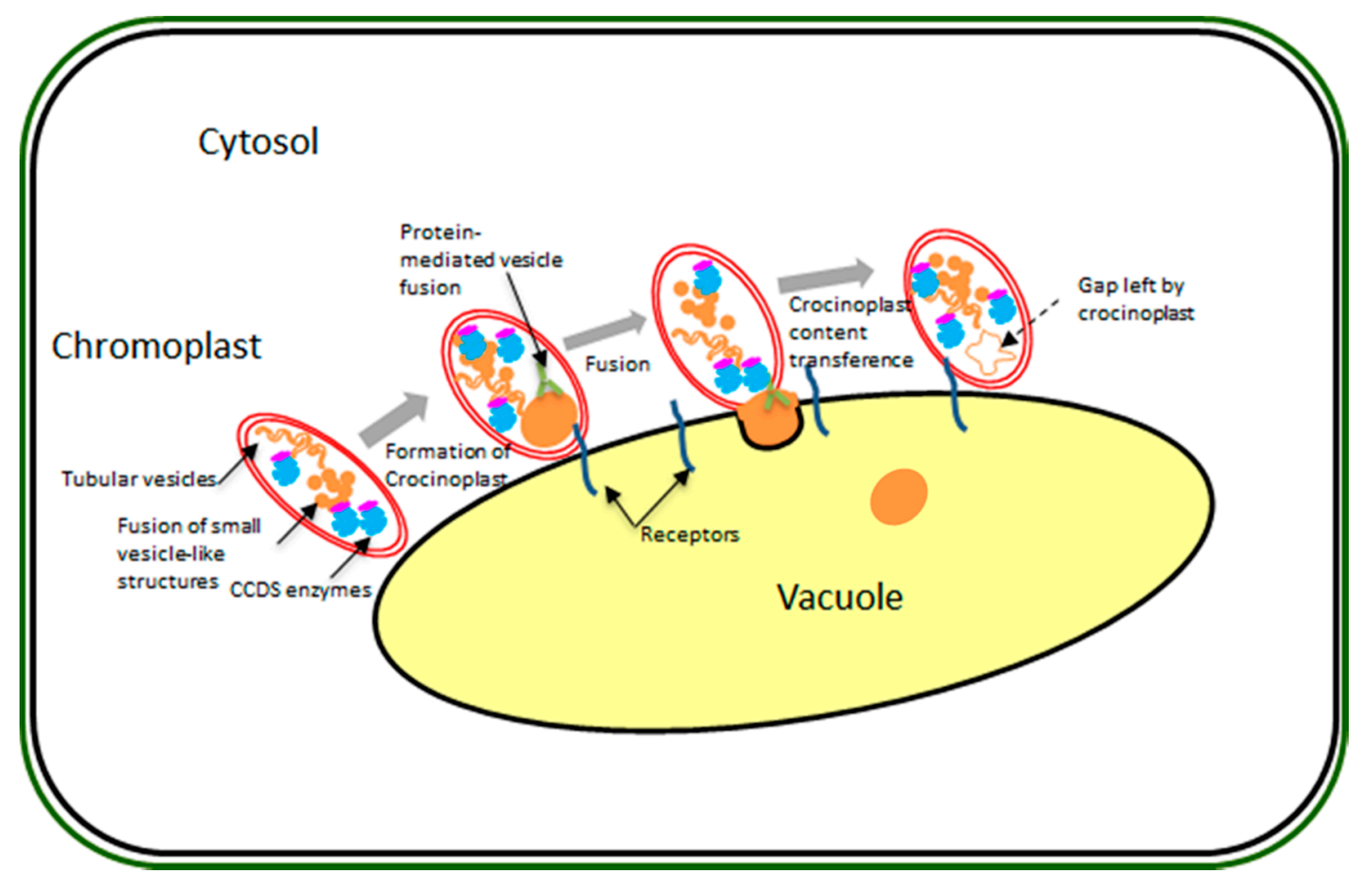

Figure 8. Proposed model of crocin transport from chromoplast to the vacuole.

Understanding the biosynthesis, transport and storage processes of crocins fills the gap in the current knowledge regarding the metabolism of these apocarotenoids and benefits metabolic engineering which could use these compounds in heterologous crops for improving the nutritional quality of plant-based foods.

\section{Materials and Methods}

\subsection{Light and Transmission Electron Microscopy}

Stigmas were obtained from Crocus sativus grown under field conditions in the Botanical Garden of CLM (Albacete, Spain). We collected samples of saffron stigmas covering all the developmental stages, including the white, yellow, orange-yellow, orange, red and red-scarlet [14]. Basically, fresh stigmas from saffron plants were excised, immediately transferred to aluminum sample holders, cryoprotected with $150 \mathrm{mM}$ sucrose, frozen in a Leica EM HPM-100 high-pressure freezer (Leica Microsystems, Vienna, Austria), and then transferred to $\mathrm{LN}_{2}$. Subsequently, samples were processed as previously described by [47]. In brief, samples were freeze substituted with anhydrous acetone + $2 \% \mathrm{OsO}_{4}$ at $-80{ }^{\circ} \mathrm{C}$ for 5 days, followed by slow warming to room temperature over a period of $24 \mathrm{~h}$. After rinsing in several acetone washes, they were removed from the holders and infiltrated with increasing concentrations of Spurr resin (Ted Pella, Redding, CA, USA) in acetone according to the 
following schedule: $4 \mathrm{~h}$ in $2 \%$ resin, $4 \mathrm{~h}$ in $5 \%$ resin, $12 \mathrm{~h}$ in $10 \%, 25 \%, 50 \%, 75 \%$ resin and $36 \mathrm{~h}$ in $100 \%$ resin. We obtained poor quality freezing stigmas tissues using high pressure freezing, for this reason, they were chemically fixed in Karnovsky's fixative ( $4 \%$ formaldehyde $+5 \%$ glutaraldehyde in $0.025 \mathrm{M}$ cacodylate buffer, $\mathrm{pH}$ 6.9) for $5 \mathrm{~h}$, postfixed in $1 \% \mathrm{OsO}_{4}$ in cacodylate buffer, dehydrated in ethanol series and embedded in Spurr resin using a Leica EM TP automated tissue processor.

For both high pressure, frozen and chemically fixes samples, resin polymerization was performed at $70{ }^{\circ} \mathrm{C}$ for 1 day. Once plastic blocks were produced, thin sections $(1 \mu \mathrm{m})$ were obtained for light microscopy observation, and ultrathin $(\sim 80 \mathrm{~nm})$ sections were obtained for electron microscopy, using a Leica UC6 ultramicrotome in all the cases. Thin sections were observed unstained under phase contrast in a Nikon Eclipse E1000 microscope (Nikon, Tokyo, Japan). Ultrathin sections were mounted on formvar-coated, 200 mesh copper grids, stained with uranyl acetate and lead citrate, and observed in a Jeol JEM 1010 transmission electron microscope (Jeol, Tokyo, Japan).

\subsection{Isolation and Purification of Saffron Chromoplasts from Fresh Stigmas}

For chromoplast isolation, three biological replicates were processed and analyzed independently. Chromoplasts were isolated from fresh saffron stigmas at the red stage (about $30 \mathrm{~g}$ ) following the method described by Angaman et al. [48]. Briefly, $30 \mathrm{~g}$ stigmas were mixed with $60 \mathrm{~mL}$ of buffer A (100 mM Tris-HCl pH 8.2, $0.33 \mathrm{M}$ sorbitol, $2 \mathrm{mM} \mathrm{MgCl}$, $10 \mathrm{mM} \mathrm{KCl}, 8 \mathrm{mM}$ EDTA, $10 \mathrm{mM}$ ascorbic acid, $5 \mathrm{mM}$ L-cysteine, $1 \mathrm{mM}$ PMSF, 1\% PVPP and $1 \mathrm{mM}$ DTT). Then after, the obtained puree was homogenized with a Waring blender and filtered through 8 layers of gauze and then through 2 layers of cheesecloth. The homogenate was mixed and centrifuged for $2 \mathrm{~min}$ at $200 \times \mathrm{g}$. The supernatant was recovered and centrifuged for $10 \mathrm{~min}$ at $5000 \times \mathrm{g}$. The obtained pellet was resuspended in $50 \mathrm{~mL}$ of buffer B (buffer A without PVPP) and centrifuged for $10 \mathrm{~min}$ at $5000 \times \mathrm{g}$. The pellet was resuspended in $4 \mathrm{~mL}$ of buffer $\mathrm{B}$ and chromoplasts were fractionated by ultracentrifugation on a discontinuous sucrose gradient $(15 \%, 30 \%, 40 \%, 50 \%$ and $60 \%$ in Tris- $\mathrm{HCl} \mathrm{pH} 7.4$ supplemented with $1 \mathrm{mM}$ DTT) for $1 \mathrm{~h}$ at $100,000 \times \mathrm{g}$. Chromoplast fractions were recovered by gentle aspiration with a Pasteur pipette. The collected fractions were washed with one volume of buffer $B$ and chromoplasts were recovered by centrifugation $(10 \mathrm{~min}, 5000 \times g)$.

\subsection{Extraction and Analysis of Crocins by HPLC-DAD, Marker-Enzyme Assays and Sequence Analysis}

The collected fractions were extracted with $1 \mathrm{~mL}$ Tris- $\mathrm{HCl}(50 \mathrm{mM}, \mathrm{pH} 7.5$; containing $1 \mathrm{M} \mathrm{NaCl})$, and incubated for $10 \mathrm{~min}$ on ice. One volume of $\mathrm{CHCl}_{3}$ was then added, mixed, and the extract incubated on ice for an additional $10 \mathrm{~min}$ followed by centrifugation at $3000 \times \mathrm{g}$ for $5 \mathrm{~min}$ at $4{ }^{\circ} \mathrm{C}$. The lower $\mathrm{CHCl}_{3}$ phase was evaporated under $\mathrm{N}_{2}$ gas and the dried residues were stored together with the upper aqueous phases at $-80{ }^{\circ} \mathrm{C}$ until analysis by HPLC. All assays were performed in triplicate. The HPLC methods used for the analysis and detection of glycosylated apocarotenoids and carotenoids have been previously described [4,14].

The activity of the enzymes succinate dehydrogenase, catalase and alcohol dehydrogenase was measured in purified chromoplast samples (resuspended in buffer B). Succinate dehydrogenase and catalase activities were measured in samples previously treated with $1 \%$ Triton X-100 for $10 \mathrm{~min}$ at $4{ }^{\circ} \mathrm{C}$. The assay methods used for enzyme activities were those described by [48]. Marker-enzyme assay determinations were done in duplicate using two independent chromoplast preparations. MapMan Bins (available on: http:/ / mapman.mpimp-golm.mpg.de) and Venn diagram (available on: http:/ / bioinformatics.psb.ugent.be/webtools/Venn/) were used for functional assignments and for comparison, respectively.

\subsection{LC-MS/MS as an Analytical Method for the Identification of Chromoplast Proteins}

Protein samples were processed and analyzed by nanoLC-MS/MS. In brief, salts and non-protein components were removed prior to proteomic analysis by means of a short electrophoretic run (10 min). The protein band was excised, cut into small pieces and destained with $50 \mathrm{mM}$ ammonium 
bicarbonate $/ 50 \%$ ACN (acetonitrile), dehydrated with ACN and dried. Samples were reduced by adding dithiothreitol to a final concentration of $10 \mathrm{mM}$ and alkylated with iodoacetamide to a final concentration of $50 \mathrm{mM}$. Then, gel pieces were dried, rehydrated with $12.5 \mathrm{ng} / \mu \mathrm{L}$ trypsin in $50 \mathrm{mM}$ ammonium bicarbonate and incubated overnight at $30^{\circ} \mathrm{C}$. Peptides were extracted at $37^{\circ} \mathrm{C}$ using ACN and 0.5\% TFA, and then dried, cleaned using ZipTip with $0.6 \mu \mathrm{L} \mathrm{C18}$ resin (Millipore, Darmstadt, Germany) and reconstituted in $5 \mu \mathrm{L} 0.1 \%$ formic acid $/ 2 \%$ ACN prior to MS analysis. All peptide separations were carried out on a NanoEasy HPLC (Proxeon Biosystems, Odense, Denmark) coupled to a nanoelectrospray ion source (Proxeon Biosystems). Six microliters of each sample were loaded onto a C18-A1 ASY-Column $2 \mathrm{~cm}$ precolumn (Thermo Scientific, Madrid, Spain) and then eluted onto a Biosphere $\mathrm{C} 18$ column (C18, inner diameter $75 \mu \mathrm{m}, 15 \mathrm{~cm}$ long, $3 \mu \mathrm{m}$ particle size, Nano Separations, Nieuwkoop, The Netherlands). The mobile phase flow rate was $250 \mathrm{~nL} / \mathrm{min}$, and $0.1 \%$ formic acid, $2 \% \mathrm{ACN}$ in water (solvent $\mathrm{A}$ ) and $0.1 \%$ formic acid and $100 \% \mathrm{ACN}$ (solvent B) were used as eluents. The gradient profile was set as follows: $0 \%-45 \%$ solvent B for $130 \mathrm{~min}, 45 \%-95 \%$ solvent B for $15 \mathrm{~min}$ and $5 \mathrm{~min}$ isocratically at $95 \%$. Mass spectra were acquired on the LTQ-Orbitrap Velos in the positive ion mode. Full-scan MS spectra $(m / z 300-1900)$ were acquired in the Orbitrap with a target value of 1,000,000 at a resolution of 60,000 and the 15 most intense ions were selected for collision induced dissociation (CID) fragmentation in the LTQ with a target value of 10,000 and normalized collision energy of $35 \%$.

Mass spectra * raw files were searched against the Magnoliophyta $(2,057,887$ sequences) and Crocus (513 sequences) databases from UniProtKB (available on: http://www.uniprot.org/) using the SEQUEST search engine through Proteome Discoverer (version 1.3.0.339, Thermofisher, Madrid, Spain) and then the results were merged and checked manually for further analyses to avoid redundancy. Precursor and fragments mass tolerance were set to $10 \mathrm{ppm}$ and $0.8 \mathrm{Da}$, respectively. Search parameters included a maximum of two missed cleavages allowed, carbamidomethylation of cysteines as a fixed modification and oxidation of methionine as a variable modification. Peptides were validated through the algorithm Percolator (FDR 0.01) [49] and only those with high and medium confidence were admitted. Protein identifications were accepted if they contained at least two identified peptides, except for proteins involved in the crocins pathway. CD-HIT web server (available on: http:// weizhong-lab.ucsd.edu/cdhit_suite/cgi-bin/index.cgi?cmd=cd-hit) was used to search for sequences redundancy with a sequence identity cut-off of 0.9 .

\subsection{Gene Expression by Quantitative Reverse Transcription-PCR ( $q R T-P C R$ )}

The gene-specific oligonucleotides used for expression analysis are listed in Table S3. The qRT-PCR was carried out on cDNA from five developmental stages selected from stigma at the white, yellow, orange, red and anthesis stages. Three biological replicates were achieved and reactions were set up in a final volume of $25 \mu \mathrm{L}$ in GoTaq ${ }^{\circledR}$ qPCR Master Mix (Promega, Madison, WI, USA) according to manufacturer's instructions. The constitutively expressed 18SrRNA gene was used as a reference gene. The cycling parameters were used as described in [21].

\subsection{Bioinformatic Analysis}

Heat map, hierarchical clustering (HCL) and correlation matrix were drawn by using GENE-E (available on: http://www.broadinstitute.org/cancer/software/GENE-E/), while correlation networks were performed as previously described [50] with slight modifications: force-directed layout was used, as well as visualization using crocetin and crocins as central hubs and building edge length inversely proportional to the Pearson correlation coefficient $(|p|)$.

\section{Conclusions}

Crocins, the glucosides of crocetin, are present at high concentrations in the stigmas of saffron. Crocins biogenesis starts with zeaxanthin cleavage by CCD2, followed by the activity of an uncharacterized $\mathrm{ADH}$, and is further glucosylated by CsUGT2. The generated crocins accumulate in the 
vacuole. Variations at the cytological level that go along with the massive synthesis and accumulation of these apocarotenoids, and especially the differentiation and evolution of chromoplasts throughout the development of saffron stigmas, have hardly been studied. The data obtained by monitoring chromoplast development during stigma growth by means of transmission electron microscopy revealed the presence of a membranous network spanning the entire plastid volume together with the presence of plastoglobules defined the conversion of plastids into chromoplasts. Our data showed a direct transfer from large globule (crocinoplast) to the central vacuole in the later developmental stages. A first draft of the stigma proteome was depicted, which allowed the identification of several well-known plastid proteins and new candidates involved in crocetin metabolism. Results from correlation analyses on a set of variables including three apocarotenoid metabolites (crocetin, crocins and picrocrocin), as well transcripts of carotenoid/apocarotenoid biosynthesis, plastid development and starch metabolism, showed a coordinate regulation in the expression of pathways boosting carotenoid and apocarotenoid synthesis and involved in the chromoplast formation and development. The data obtained from this study represent a resource for a better comprehension of saffron physiology and metabolism.

Supplementary Materials: Supplementary materials can be found at www.mdpi.com/1422-0067/18/1/76/s1.

Acknowledgments: This work was supported by the Spanish Ministerio de Economía y Competitividad (BIO2013-44239-R), participates in the IBERCAROT network (112RT0445) and benefited from the networking activities within the European Cooperation in Science and Technology Action CA15136 (EUROCAROTEN). The proteomics analysis LC-MS/MS by LTQ Orbitrap Velos was carried out in the Proteomics and Genomics Facility (CIB-CSIC), a member of ProteoRed-ISCIII network. We wish to thank Javier Argandoña and Carmen Cifuentes for technical assistance and Kathy Walsh for language revision.

Author Contributions: Oussama Ahrazem and Lourdes Gómez-Gómez conceived and designed the experiments with the help of Rosa Victoria Molina and Gianfranco Diretto. Verónica Parra-Vega, Alba Rivas-Sendra, Claudia Pallotti, Jose M. Seguí-Simarro and Rosa Victoria Molina performed the light and transmission electron microscopy experiments. Ángela Rubio-Moraga, Oussama Ahrazem and Lourdes Gómez-Gómez achieved the isolation and purification of saffron chromoplasts, contributed to the preparation of the RNA samples and performed the qRT-PCR experiments. Alicia Prieto performed the LC-MS/MS analyses. Gianfranco Diretto achieved the statistical and bioinformatics analyses. Oussama Ahrazem, Rosa Victoria Molina, Gianfranco Diretto and Lourdes Gómez-Gómez analyzed the data, wrote the manuscript. All the authors contributed to the discussion and approved the final manuscript.

Conflicts of Interest: The authors declare no conflict of interest.

\section{References}

1. Schmidt, M.; Betti, G.; Hensel, A. Saffron in phytotherapy: Pharmacology and clinical uses. Wien. Med. Wochenschr. 2007, 157, 315-319. [CrossRef] [PubMed]

2. Bathaie, S.Z.; Mousavi, S.Z. New applications and mechanisms of action of saffron and its important ingredients. Crit. Rev. Food Sci. Nutr. 2010, 50, 25. [CrossRef] [PubMed]

3. Zhang, Z.; Wang, C.-Z.; Wen, X.-D.; Shoyama, Y.; Yuan, C.-S. Role of saffron and its constituents on cancer chemoprevention. Pharm. Biol. 2013, 51, 920-924. [CrossRef] [PubMed]

4. Castillo, R.; Fernández, J.-A.; Gómez-Gómez, L. Implications of carotenoid biosynthetic genes in apocarotenoid formation during the stigma development of crocus sativus and its closer relatives. Plant Physiol. 2005, 139, 674-689. [CrossRef] [PubMed]

5. Rubio-Moraga, A.; Ahrazem, O.; Rambla, J.L.; Granell, A.; Gomez-Gomez, L. Crocins with high levels of sugar conjugation contribute to the yellow colours of early-spring flowering crocus tepals. PLoS ONE 2013, 8, e71946. [CrossRef] [PubMed]

6. Ahrazem, O.; Rubio-Moraga, A.; Lopez, R.C.; Gomez-Gomez, L. The expression of a chromoplast-specific lycopene $\beta$ cyclase gene is involved in the high production of saffron's apocarotenoid precursors. J. Exp. Bot. 2010, 61, 105-119. [CrossRef] [PubMed]

7. Pfander, H.; Schurtenberger, H. Biosynthesis of c20-carotenoids in Crocus sativus. Phytochemistry 1982, $21,4$. [CrossRef] 
8. Ahrazem, O.; Rubio-Moraga, A.; Berman, J.; Capell, T.; Christou, P.; Zhu, C.; Gómez-Gómez, L. The carotenoid cleavage dioxygenase CCD2 catalyzing the synthesis of crocetin in spring crocuses and saffron is a plastidial enzyme. New Phytol. 2016, 209, 650-663. [CrossRef] [PubMed]

9. Frusciante, S.; Diretto, G.; Bruno, M.; Ferrante, P.; Pietrella, M.; Prado-Cabrero, A.; Rubio-Moraga, A.; Beyer, P.; Gomez-Gomez, L.; Al-Babili, S.; et al. Novel carotenoid cleavage dioxygenase catalyzes the first dedicated step in saffron crocin biosynthesis. Proc. Natl. Acad. Sci. USA 2014, 111, 12246-12251. [CrossRef] [PubMed]

10. Moraga, A.R.; Nohales, P.F.; Perez, J.A.; Gomez-Gomez, L. Glucosylation of the saffron apocarotenoid crocetin by a glucosyltransferase isolated from crocus sativus stigmas. Planta 2004, 219, 955-966. [CrossRef] [PubMed]

11. Grilli-Caiola, M.; Canini, A. Saffron reproductive biology. Acta Hortic. 2004, 650, 11. [CrossRef]

12. Bréhélin, C.; Kessler, F.; van Wijk, K.J. Plastoglobules: Versatile lipoprotein particles in plastids. Trends Plant Sci. 2007, 12, 260-266. [CrossRef] [PubMed]

13. Egea, I.; Barsan, C.; Bian, W.; Purgatto, E.; Latché, A.; Chervin, C.; Bouzayen, M.; Pech, J.-C. Chromoplast differentiation: Current status and perspectives. Plant Cell Physiol. 2010, 51, 1601-1611. [CrossRef] [PubMed]

14. Rubio, A.; Rambla, J.L.; Santaella, M.; Gómez, M.D.; Orzaez, D.; Granell, A.; Gómez-Gómez, L. Cytosolic and plastoglobule-targeted carotenoid dioxygenases from Crocus sativus are both involved in $\beta$-ionone release. J. Biol. Chem. 2008, 283, 24816-24825. [CrossRef] [PubMed]

15. Nesvizhskii, A.I. A survey of computational methods and error rate estimation procedures for peptide and protein identification in shotgun proteomics. J. Proteom. 2010, 73, 2092-2123. [CrossRef] [PubMed]

16. Ning, K.; Fermin, D.; Nesvizhskii, A.I. Comparative analysis of different label-free mass spectrometry based protein abundance estimates and their correlation with RNA-seq gene expression data. J. Proteome Res. 2012, 11, 2261-2271. [CrossRef] [PubMed]

17. Zhang, Y.; Yin, H.; Lu, H. Recent progress in quantitative glycoproteomics. Glycoconj. J. 2012, $29,249-258$. [CrossRef] [PubMed]

18. Paredi, G.; Raboni, S.; Marchesani, F.; Ordoudi, S.A.; Tsimidou, M.Z.; Mozzarelli, A.; McPhee, D.J. Insight of saffron proteome by gel-electrophoresis. Molecules 2016, 21, 167. [CrossRef] [PubMed]

19. Ruiz-Sola, M.Á.; Rodríguez-Concepción, M. Carotenoid biosynthesis in arabidopsis: A colorful pathway. Arabidopsis Book 2012, 10, e0158. [CrossRef] [PubMed]

20. Kim, J.-E.; Cheng, K.M.; Craft, N.E.; Hamberger, B.; Douglas, C.J. Over-expression of arabidopsis thaliana carotenoid hydroxylases individually and in combination with a $\beta$-carotene ketolase provides insight into in vivo functions. Phytochemistry 2010, 71, 168-178. [CrossRef] [PubMed]

21. Rubio-Moraga, A.; Ahrazem, O.; Perez-Clemente, R.M.; Gomez-Cadenas, A.; Yoneyama, K.; Lopez-Raez, J.A.; Molina, R.V.; Gomez-Gomez, L. Apical dominance in saffron and the involvement of the branching enzymes CCD7 and CCD8 in the control of bud sprouting. BMC Plant Biol. 2014, 14, 171. [CrossRef] [PubMed]

22. Rameau, C. Strigolactones, a novel class of plant hormone controlling shoot branching. C. R. Biol. 2010, 333, 344-349. [CrossRef] [PubMed]

23. Li, L.; van Eck, J. Metabolic engineering of carotenoid accumulation by creating a metabolic sink. Transgenic Res. 2007, 16, 581-585. [CrossRef] [PubMed]

24. Zhou, X.; Welsch, R.; Yang, Y.; Álvarez, D.; Riediger, M.; Yuan, H.; Fish, T.; Liu, J.; Thannhauser, T.W.; Li, L. Arabidopsis or proteins are the major posttranscriptional regulators of phytoene synthase in controlling carotenoid biosynthesis. Proc. Natl. Acad. Sci. USA 2015, 112, 3558-3563. [CrossRef] [PubMed]

25. Sitte, P. Development and division of chromoplasts in petals of forsythia. Cellule 1987, 74, 59-77.

26. Lee, W.D.; Hsu, J.J.; Huang, F.C.; Chao, M.C.; Chang, Y.L.; Huang, M.H. Ischemic stroke in williams-beuren syndrome: A case report. Kaohsiung J. Med. Sci. 2009, 25, 212-216. [CrossRef]

27. Funes, S.; Gerdes, L.; Inaba, M.; Soll, J.; Herrmann, J.M. The arabidopsis thaliana chloroplast inner envelope protein artemis is a functional member of the Alb3/Oxa1/YidC family of proteins. FEBS Lett. 2004, 569, 89-93. [CrossRef] [PubMed]

28. Ajjawi, I.; Coku, A.; Froehlich, J.E.; Yang, Y.; Osteryoung, K.W.; Benning, C.; Last, R.L. A j-like protein influences fatty acid composition of chloroplast lipids in arabidopsis. PLoS ONE 2011, 6, e25368. [CrossRef] [PubMed] 
29. Billings, S.E.; Pierzchalski, K.; Tjaden, N.E.B.; Pang, X.-Y.; Trainor, P.A.; Kane, M.A.; Moise, A.R. The retinaldehyde reductase DHRS3 is essential for preventing the formation of excess retinoic acid during embryonic development. FASEB J. 2013, 27, 4877-4889. [CrossRef] [PubMed]

30. Díaz-Sánchez, V.; Estrada, A.F.; Trautmann, D.; Al-Babili, S.; Avalos, J. The gene carD encodes the aldehyde dehydrogenase responsible for neurosporaxanthin biosynthesis in Fusarium fujikuroi. FEBS J. 2011, 278, 3164-3176. [CrossRef] [PubMed]

31. Zhao, D.; McCaffery, P.; Ivins, K.J.; Neve, R.L.; Hogan, P.; Chin, W.W.; Dräger, U.C. Molecular identification of a major retinoic-acid-Synthesizing enzyme, a retinaldehyde-Specific dehydrogenase. Eur. J. Biochem. 1996, 240, 15-22. [CrossRef] [PubMed]

32. Díaz-Sánchez, V.; Limón, M.C.; Schaub, P.; Al-Babili, S.; Avalos, J. A raldh-like enzyme involved in fusarium verticillioides development. Fungal Genet. Biol. 2016, 86, 20-32. [CrossRef] [PubMed]

33. Wang, Y.Q.; Yang, Y.; Fei, Z.; Yuan, H.; Fish, T.; Thannhauser, T.W.; Mazourek, M.; Kochian, L.V.; Wang, X.; $\mathrm{Li}, \mathrm{L}$. Proteomic analysis of chromoplasts from six crop species reveals insights into chromoplast function and development. J. Exp. Bot. 2013, 64, 949-961. [CrossRef] [PubMed]

34. Barsan, C.; Sanchez-Bel, P.; Rombaldi, C.; Egea, I.; Rossignol, M.; Kuntz, M.; Zouine, M.; Latche, A.; Bouzayen, M.; Pech, J.C. Characteristics of the tomato chromoplast revealed by proteomic analysis. J. Exp. Bot. 2010, 61, 2413-2431. [CrossRef] [PubMed]

35. Neuhaus, H.; Emes, M. Nonphotosynthetic metabolism in plastids. Annu. Rev. Plant Biol. 2000, 51, 111-140. [CrossRef] [PubMed]

36. Bouvier, F.; Camara, B. The role of plastids in ripening fruits. In The Structure and Function of Plastids; Springer: Dordrecht, The Netherlands, 2006; pp. 419-432.

37. Cao, H.; Wang, J.; Dong, X.; Han, Y.; Ma, Q.; Ding, Y.; Zhao, F.; Zhang, J.; Chen, H.; Xu, Q. Carotenoid accumulation affects redox status, starch metabolism, and flavonoid/anthocyanin accumulation in citrus. BMC Plant Biol. 2015, 15, 27. [CrossRef] [PubMed]

38. Kilambi, H.V.; Kumar, R.; Sharma, R.; Sreelakshmi, Y. Chromoplast-specific carotenoid-associated protein appears to be important for enhanced accumulation of carotenoids in hp1 tomato fruits. Plant Physiol. 2013, 161, 2085-2101. [CrossRef] [PubMed]

39. Lu, S.; van Eck, J.; Zhou, X.; Lopez, A.B.; O’Halloran, D.M.; Cosman, K.M.; Conlin, B.J.; Paolillo, D.J.; Garvin, D.F.; Vrebalov, J. The cauliflower Or gene encodes a DnaJ cysteine-rich domain-containing protein that mediates high levels of $\beta$-carotene accumulation. Plant Cell 2006, 18, 3594-3605. [CrossRef] [PubMed]

40. Simkin, A.J.; Gaffé, J.; Alcaraz, J.-P.; Carde, J.-P.; Bramley, P.M.; Fraser, P.D.; Kuntz, M. Fibrillin influence on plastid ultrastructure and pigment content in tomato fruit. Phytochemistry 2007, 68, 1545-1556. [CrossRef] [PubMed]

41. Langenkämper, G.; Manac'h, N.; Broin, M.; Cuiné, S.; Becuwe, N.; Kuntz, M.; Rey, P. Accumulation of plastid lipid-associated proteins (fibrillin/CDSP34) upon oxidative stress, ageing and biotic stress in solanaceae and in response to drought in other species. J. Exp. Bot. 2001, 52, 1545-1554. [CrossRef] [PubMed]

42. Kreuz, K.; Beyer, P.; Kleinig, H. The site of carotenogenic enzymes in chromoplasts from Narcissus pseudonarcissus L. Planta 1982, 154, 66-69. [CrossRef] [PubMed]

43. Ljubesić, N.; Wrischer, M.; Devidé, Z. Chromoplasts-The last stages in plastid development. Int. J. Dev. Biol. 1991, 35, 251-258. [PubMed]

44. Louro, R.P.; Santiago, L.J. Development of carotenoid storage cells in Bixa orellana L. seed arils. Protoplasma 2015, 253, 77-86. [CrossRef] [PubMed]

45. Weber, R.W.; Davoli, P. Autophagocytosis of carotenoid-rich lipid droplets into vacuoles during aeciospore ageing in Puccinia distincta. New Phytol. 2002, 154, 471-479. [CrossRef]

46. Corral-Martínez, P.; Parra-Vega, V.; Seguí-Simarro, J.M. Novel features of Brassica napus embryogenic microspores revealed by high pressure freezing and freeze substitution: Evidence for massive autophagy and excretion-based cytoplasmic cleaning. J. Exp. Bot. 2013. [CrossRef] [PubMed]

47. Seguí-Simarro, J.M. High-pressure freezing and freeze substitution of in vivo and in vitro cultured plant samples. In Plant Microtechniques and Protocols; Yeung, E., Stasolla, C., Sumner, M., Huang, B., Eds.; Springer International Publishing: Switzerland, 2015; pp. 117-134.

48. Angaman, D.M.; Petrizzo, R.; Hernandez-Gras, F.; Romero-Segura, C.; Pateraki, I.; Busquets, M.; Boronat, A. Precursor uptake assays and metabolic analyses in isolated tomato fruit chromoplasts. Plant Methods 2012, 8, 1. [CrossRef] [PubMed] 
49. Salvachúa, D.; Martínez, A.T.; Tien, M.; López-Lucendo, M.F.; García, F.; de Los Ríos, V.; Martínez, M.J.; Prieto, A. Differential proteomic analysis of the secretome of Irpex lacteus and other white-rot fungi during wheat straw pretreatment. Biotechnol. Biofuels 2013, 6, 115. [CrossRef] [PubMed]

50. Diretto, G.; Al-Babili, S.; Tavazza, R.; Scossa, F.; Papacchioli, V.; Migliore, M.; Beyer, P.; Giuliano, G. Transcriptional-metabolic networks in $\beta$-carotene-enriched potato tubers: The long and winding road to the golden phenotype. Plant Physiol. 2010, 154, 899-912. [CrossRef] [PubMed]

(C) 2017 by the authors; licensee MDPI, Basel, Switzerland. This article is an open access article distributed under the terms and conditions of the Creative Commons Attribution (CC-BY) license (http://creativecommons.org/licenses/by/4.0/). 